\title{
Animal-Assisted Interventions for the Improvement of Mental Health Outcomes in Higher Education Students: A Systematic Review of Randomised Controlled Trials
}

\author{
Charlotte Parbery-Clark ${ }^{1,2, *}$, Marvellas Lubamba ${ }^{1}$, Louise Tanner ${ }^{1}$ and Elaine McColl ${ }^{1}$ (D) \\ 1 Population Health Sciences Institute, Newcastle University, Newcastle upon Tyne NE1 7RU, UK; \\ lubamba@ualberta.ca (M.L.); louise.tanner@newcastle.ac.uk (L.T.); elaine.mccoll@newcastle.ac.uk (E.M.) \\ 2 Newcastle City Council, Civic Centre, Newcastle upon Tyne NE1 8QH, UK \\ * Correspondence: charlotte.parbery-clark@newcastle.ac.uk
}

check for

updates

Citation: Parbery-Clark, C.; Lubamba, M.; Tanner, L.; McColl, E.

Animal-Assisted Interventions for the Improvement of Mental Health Outcomes in Higher Education Students: A Systematic Review of Randomised Controlled Trials. Int. J. Environ. Res. Public Health 2021, 18, 10768. https://doi.org/10.3390/ ijerph182010768

Academic Editor: Paul B. Tchounwou

Received: 8 August 2021

Accepted: 8 September 2021

Published: 14 October 2021

Publisher's Note: MDPI stays neutral with regard to jurisdictional claims in published maps and institutional affiliations.

Copyright: (c) 2021 by the authors. Licensee MDPI, Basel, Switzerland. This article is an open access article distributed under the terms and conditions of the Creative Commons Attribution (CC BY) license (https:/ / creativecommons.org/licenses/by/ $4.0 /)$.

\begin{abstract}
Background: The aim of this systematic review was to evaluate the effectiveness of Animal-Assisted Interventions (AAIs), particularly Animal-Assisted Therapy (AAT) and AnimalAssisted Activity (AAA), in improving mental health outcomes for students in higher education. The number of students in higher education reporting mental health problems and seeking support from universities' student support services has risen over recent years. Therefore, providing engaging interventions, such as AAIs, that are accessible to large groups of students are attractive. Methods: MEDLINE, PsycINFO, Embase and Cochrane Library were searched from relative inception to end of April 2020. Additionally, a grey literature search was undertaken. Independent screening, data extraction and risk of bias assessment were completed, with varying percentages, by two reviewers. Results: After de-duplication, 6248 articles were identified of which 11 studies were included in the narrative synthesis. The evidence from randomised controlled trials suggests that AAIs could provide short-term beneficial results for anxiety in students attending higher education but with limited evidence for stress, and inconclusive evidence for depression, well-being and mood. For the non-statistically significant results, the studies either did not include a power calculation or were under-powered. Conclusions: Potential emerging evidence for the short-term benefits of AAI for anxiety, and possibly stress, for students in higher education was found.
\end{abstract}

Keywords: animal-assisted interventions; mental health outcomes; stress; anxiety; higher education; systematic review

\section{Introduction}

Attending higher education commonly represents a major life transition for young people, with it often being the first time living away from the family home, which can bring social, financial and academic stressors [1,2]. The true prevalence of mental health problems for students in higher education is hard to estimate accurately. For example, in the UK, there is a scarcity of large-scale studies being truly representative of the UK student population in higher education or applying a weighted adjustment to accommodate for the lack of representativity $[3,4]$. However, the number of students in higher education disclosing mental health problems and accessing higher education institutions' (HEI) support services has risen in recent years [1]. Disclosure and requesting support can result in long waiting lists for more traditional individualised therapy sessions, while stigma around seeking help for mental health and well-being is still present $[5,6]$. Therefore, a possible solution may be the provision of interventions aimed at reducing stress and anxiety as well as boosting mental health and well-being that are appealing, effective, and accessible to large groups of students [6]. In this respect, part of the solution could be Animal Assisted Interventions (AAIs). 
AAI is an umbrella term that describes the use of various animal species in numerous ways that are beneficial to humans, and includes Animal-Assisted Therapy (AAT), Animal-Assisted Education (AAE), Animal-Assisted Activity (AAA) and more recently, Animal-Assisted Coaching (AAC) [7-9]. In summary, AAT is a structured and goal-directed intervention with a specifically trained live animal and is designed to ameliorate socioemotional, behavioural, cognitive and/or physical functioning $[7,8]$. AAA is a planned informal interaction with human-animal teams for recreational, motivational and educational opportunities $[7,8]$. AAE, similarly structured to AAT, focuses on specific educational or academic goals with a professional trained in, and with expertise, in education or a similar field [7,8]. AAC is also similarly structured to AAT and AAE but delivered by licensed coaches focusing on personal growth [8]. AAIs' popularity have risen over recent years, and they are used in diverse settings such as hospitals, nursing homes, schools and universities [10-14]. Positive interactions with animals have been shown to have beneficial human physiological responses, such as reduction in heart rate, blood pressure, stress hormones (for example, cortisol), and increase in hormones associated with positive emotions (for example, oxytocin) [15-18]. Evidence has emerged that AAIs, particularly AAT, may be effective in treating various mental health conditions (such as schizophrenia, depression and drug/alcohol addiction), developmental disorders (such as autism-spectrum disorder) and depressive symptoms in individuals with certain neurological conditions (such as dementia) $[10,11,14,19]$. Furthermore, a recent meta-analysis, involving both children and adults, demonstrated statistically significant improvements in heart rate, self-reported anxiety and stress, but not blood pressure, after AAIs [20]. The discrepancies in findings related to BP may be due to psychological arousal and do not necessarily contradict the stress relieving effects [21].

There are numerous theories of why and how AAIs may work. For example, Crossman et al. [6] suggests various theories for how animals may reduce stress including:

- emotional contagion (transmitting the animal's positive emotions onto humans)

- facilitating social interaction

- opportunities for reinforcement (by partaking in pleasurable activities and experiencing positive emotions)

- evoking expectations that participation will reduce stress (expectancy that the intervention will work)

Beck [22] describes that the human-animal bond is rooted in evolutionary as well as physiological and psychological processes with significant health benefits for both humans and animals. Furthermore, the importance, in the psychosocial model, of social support for health and how social support can function as a buffer against stress are also relevant $[23,24]$. The animal-human bond can be considered as a type of social relationship, which can offer this type of support. Some individuals may form an animal-human bond more readily than a human-human bond as animals are considered to be indifferent and non-judgemental to an individual's appearance, social skills or socioeconomic status (SES) [25]. Furthermore, the Biophilia Theory proposes that humans are drawn to interact with animals due to an innate desire to connect with living organisms and nature $[25,26]$. Additionally, distraction as a cognitive refocus may also contribute, though this research has mostly focused on anxiety and pain whilst awaiting or receiving medical treatment [27].

Interestingly, the prevalence of programmes using AAIs at HEIs has increased, for example by 2015 over 900 existed in the USA [6]. In the UK, these types of programmes have also risen in popularity with various forms being implemented, ranging from oneday events to specific sessions [28-32]. Additionally, the evidence-base for using AAIs with this population is growing with persuasive descriptive and anecdotal reports of the benefits $[2,6,33,34]$. Over recent years, more randomised controlled trials (RCTs) have been published, evaluating the effectiveness of AAIs in respect of various outcomes for students in higher education [35-37]. Nonetheless, a lack of completed systematic reviews for AAIs and this specific population exists. Therefore, to our knowledge, no completed systematic reviews were identified that primarily evaluate the effectiveness of AAIs, particularly AAT 
and AAA, delivered in multiple or single sessions, in improving mental health outcomes for students in higher education, with no age or course restrictions. This systematic review addresses this gap in the literature to help inform HEI providers regarding the potential benefits of AAIs for students' mental health and well-being, as well as to provide recommendations for future policy, practices and research.

\section{Aim and Objectives}

The aim of this systematic review was to evaluate the effectiveness of AAIs, particularly AAT and AAA, in improving mental health outcomes for students in higher education. The objectives were to:

- $\quad$ systematically search and critically appraise the relevant published and unpublished literature on the effectiveness of AAIs, particularly AAT and AAA, in improving mental health outcomes for this particular population.

- provide evidenced-based recommendations for policy, practice and further research.

\section{Methods}

\subsection{Protocol and Ethics}

A scoping review defined the focus of this systematic review by identifying gaps in the literature. This included searches for published literature in MEDLINE, The Cochrane Library, PsychINFO and Campbell Collaboration, as well as PROSPERO and Joanna Briggs Institute's Systematic Review Register. The protocol for this systematic review was peerreviewed and registered on the PROSPERO database on 25 June 2020 (registration number CRD42020186541) [38]. The Preferred Reporting Items for Systematic Reviews and MetaAnalyses (PRISMA) guidelines were followed [39]. Ethics approval was not required.

\subsection{Search Strategy}

The search strategy was independently peer-reviewed by both an information specialist and an experienced librarian at Newcastle University. The full search strategies are included in Appendix A. The search strategies were not limited by year, study design, language or publication status. MEDLINE, PsycINFO, Embase and Cochrane Library with inclusion of Central Register of Controlled Trials CENTRAL, Cochrane Database of Systematic Reviews and Cochrane Clinical Answers were searched from their relative inception to week three of April/week commencing 27 April 2020. Additionally, an Advanced Google search, using the first four pages due to Google sorting by relevance, during the week ending the 1 May 2020, as well as a further search in the PROSPERO database were completed. To identify additional studies, the reference lists of all full manuscripts meeting eligibility criteria and a "cited in" search using Science Citation Index/Science Citation Index Expanded via Web of Science were reviewed.

\subsection{Inclusion and Exclusion Criteria}

A description of the inclusion and exclusion criteria, according to PICOS (Population, Intervention, Comparator, Outcome and Study design), has been provided below and summarised in Table 1 [40]. During study selection, no restrictions for study geographical location, date or language were applied. 
Table 1. Summary of inclusion \& exclusion criteria with rationale $[7,8,40-46]$.

\begin{tabular}{|c|c|}
\hline Inclusion & Exclusion \\
\hline $\begin{array}{l}\text { Population: } \\
\text { Students in higher education (defined as post-secondary } \\
\text { education leading to a degree). } \\
\text { OR } \\
\text { A description of an equivalent/use of terms known to be } \\
\text { associated with higher education. } \\
\text { Rationale: Definition of higher education and represents a } \\
\text { population exposed to significant stress. } \\
\text { If stressor present, had to be an aspect of study, training, } \\
\text { education or be student-specific. } \\
\text { Rationale: student-specific stressor. }\end{array}$ & $\begin{array}{l}\text { Population: } \\
\text { Students who all have an established diagnosed } \\
\text { condition/disorder (such as autism or ADHD). } \\
\text { Rationale: could substantially affect the clinical heterogeneity of } \\
\text { the populations being compared. }\end{array}$ \\
\hline $\begin{array}{c}\text { Intervention: } \\
\text { AAI-particularly AAT and AAA. } \\
\text { OR } \\
\text { Live animal considered/called a therapy animal (OR animal } \\
\text { had training AND assessment or evaluation/certification), a } \\
\text { therapeutic goal/aim was identified, and the outcomes of } \\
\text { interest were evaluated. } \\
\text { Rationale: Key elements of AAI (including AAT and AAA); } \\
\text { evaluation of relevant outcomes was required to assess results. }\end{array}$ & $\begin{array}{c}\text { Intervention: } \\
\text { Not involving a live animal. } \\
\text { Rationale: AAIs involve live animals. } \\
\text { Participants' own } \\
\text { pets/companion/support/assistance/service animals. } \\
\text { Rationale: Likely to represent potential confounders/effect } \\
\text { modifiers and not consistent with definitions of AAI, AAT } \\
\text { or AAA. }\end{array}$ \\
\hline $\begin{array}{l}\text { Comparator: } \\
\text { A comparison group required. } \\
\text { Rationale: comparators are required to evaluate intervention's } \\
\text { effectiveness. }\end{array}$ & $\begin{array}{l}\text { Comparator: } \\
\text { No comparator. }\end{array}$ \\
\hline $\begin{array}{c}\text { Outcome: } \\
\text { Psychological using published or established } \\
\text { standardised measures: } \\
\text { Primary outcomes: effect on anxiety and/or stress. } \\
\text { Secondary outcomes: effect on depression, mood/affect } \\
\text { and well-being. } \\
\text { Rationale: Represent important measures of mental health } \\
\text { and well-being. }\end{array}$ & $\begin{array}{c}\text { Outcome: } \\
\text { Physiological. } \\
\text { Rationale: Often used as proxy measures for psychological } \\
\text { states but not directly related to psychological outcomes. } \\
\text { Educational/or academic. } \\
\text { Rationale: Focus is on mental health and well-being, } \\
\text { not performance. }\end{array}$ \\
\hline $\begin{array}{c}\text { Study: RCT and other types of randomisation. } \\
\text { Rationale: RCT represents gold standard for } \\
\text { measuring effectiveness. }\end{array}$ & $\begin{array}{l}\text { Study: all non-randomised. } \\
\text { Rationale: prone to effects of confounding \& to ensure feasibility } \\
\text { of review due to time/resources constraints. }\end{array}$ \\
\hline
\end{tabular}

The population was students in higher education with no age, course or location restrictions. Higher education was operationalised as delivered beyond secondary school leading to a degree [46]. Studies that only included students with an already established diagnosis were excluded, as this would have substantially affected the clinical heterogeneity of the studies being compared. Consequently, the intervention's true effect might have been affected by differences in the population and not the intervention itself, thereby potentially compromising the generalisability of the results [40].

Differences regarding the definitions, corresponding terminology and operating practices of the various types of AAIs can lead to difficulties assessing and comparing the interventions [7-9,47-49]. AAA and AAT are often used interchangeably in the literature, leading to ambiguity [12,49]. To overcome these identified discrepancies, both AAT and AAA were included. The definitions provided by the International Association of Human-Animal Interaction Organisations (IAHAIO) and the American Veterinary Medical Association (AVMA) to classify the various types of AAI were used $[7,8]$. In summary, AAT involves a specifically trained live animal in a planned, structured and goal-directed intervention, designed to improve socio-emotional, physical, behavioural and/or cognitive functioning of the individual(s) as part of the treatment process $[7,8]$. AAT is delivered and/or directed by a trained human professional (from education, health or human ser- 
vices) with specific expertise, and progress is measured/evaluated [7,8]. AAA is a planned informal interaction with trained animal-human teams for recreational, motivational and educational opportunities [7,8]. For the purposes of this systematic review, in accordance with IAHAIO, AAA is goal-orientated [8]. It was anticipated that studies might provide insufficient detail to objectively assess and classify the type of intervention (for example to distinguish clearly between AAT and AAA). Consequently, studies were included if the live animal was called/considered a therapy animal, a therapeutic aim/goal was identified, and the outcomes of interests were evaluated. If the term "therapy animal" had not been used, the authors had to explicitly mention that the animal had, at least, had introductory training and an assessment/evaluation [8,9]. If the intervention was part of a multi-component programme, isolating the effectiveness of the AAT/AAA had to be possible; otherwise, the study was excluded. Additionally, if a study used a stressor, the stressor had to be an aspect of study, training, education or be student specific. An exam or an experimental cognitive test that was used to emulate evaluative testing are examples of included stressors.

Any type of comparator was included, including active intervention, attention control, placebo/sham therapy, usual care/treatment as usual, or alternative active intervention. If there was more than one comparator, one was chosen according to a hierarchy that was established to assess the intervention's effectiveness [40,50]:

1. control (no-treatment, attention, usual care, or wait-list)

2. validated sham treatment (where known not to be efficacious)

3. other active intervention with known efficacy

4. sham/alternative treatments (where efficacy is unknown)

Specific psychological mental health outcomes, assessed using various established or published standardised measures, before and after the intervention were included. The primary outcomes of effect focused on anxiety and/or stress, using a range of established or published standardised measures, including but not limited to, Perceived Stress Scale (PSS) or State-Trait Anxiety Inventory (STAI) [51,52]. These outcomes were chosen as students in higher education may experience a significant amount of stress [6,53-55]. Additionally, anxiety can occur as a reaction to stress, with stress and anxiety being closely linked [56]. Differences in anxiety and/or stress scores from baseline pre-intervention to directly postintervention and/or final follow-up were included. Secondary outcomes of effect focused on mood/affect, depression and well-being, using a range of published or established standardised measures, including but not limited to, Warwick-Edinburgh Mental Wellbeing Scale (WEMWBS) or Positive and Negative Affect Schedule (PANAS) [57,58]. The time-point considered to have the biggest potential health benefit was considered as the time-point immediately after the intervention. Thereafter, the next best alternative was the time-point closest to the end of the intervention.

RCTs represent the gold standard for measuring an intervention's effectiveness with high internal validity $[59,60]$. Therefore, only RCTs were included. Studies were excluded if allocation to the respective groups was not objectively randomised, for example if randomisation was according to participants' availability, student number or date of birth with no random component. Any pilot/exploratory studies that met all inclusion criteria and analysed the outcomes of interest were included, unless the full RCT had been reported.

\subsection{Study Selection}

Following the electronic database and grey literature searches, titles and abstracts ( $n=8036)$ were de-duplicated. The remaining titles and abstracts $(n=6248)$ were cautiously screened for relevance, erring on over-inclusivity, by the first author (CPC) in Rayyan to remove obvious irrelevant studies or duplicated studies not identified by the automated systems [40,61]. Subsequently, $100 \%$ of the articles that were deemed potentially relevant $(n=928)$, were reviewed independently by two reviewers (CPC and ML, a fellow Master's student) against the pre-specified eligibility criteria using Rayyan [61]. 132 articles were identified as requiring full manuscript review, which was undertaken in full by CPC 
and $20 \%$ by ML, both blinded to the other's decisions. To identify a random $20 \%$ for $\mathrm{ML}$, the titles were arranged alphabetically in Endnote. Subsequently, a random number $(n=114)$ was generated by a true random number generator website [62]. Every fifth article (as 20\%) was chosen starting from the 114th article. If any discrepancies arose at any stage, discussion occurred between the two reviewers. If consensus was not achieved, agreement was obtained by discussing with a third reviewer (EM). If the full manuscripts were not available, title/abstract/keywords were reviewed. To meet the eligibility criteria to request an inter-library loan, at least three elements of the PICOS criteria had to be fulfilled. Keywords were identified from Rayyan, Endnote and MeSH analyser $[61,63,64]$.

\subsection{Data Extraction}

A structured Microsoft Excel data extraction form was adapted with permission of Dr. C Marshall after being piloted with two studies. The TIDieR checklist was incorporated as AAI is a complex intervention [65]. The data extraction form included [13,66]:

- $\quad$ study characteristics (such as design, setting and country)

- participants (including eligibility criteria, age, gender, and type of student)

- interventions (for example single/multiple sessions, species of animal, if handler present, duration and frequency of sessions as well as length of programme)

- outcomes (such as the relevant measures used, interpretation, results and time-points for measurements)

Data extraction with rigorous double-checking was primarily undertaken by CPC. ML independently data extracted $18 \%$ ( $n=2$ out of 11$)$. The same previously described strategy for addressing disagreements was followed, as required.

\subsection{Risk of Bias Assessment and Strength of Evidence}

A validated tool, Risk of Bias 2.0-revised (RoB2) for individually randomised parallelgroup trials, was used for the risk of bias assessment [67]. As this systematic review was aimed to inform a health policy question, the effect of interest was the effect of assignment to AAIs [68]. For each study that reported more than one of the relevant primary or secondary outcomes, a risk of bias assessment was completed for each relevant outcome. For each study that reported multiple time-points for the assessment of outcomes or had more than one comparator, one time-point and one comparator were chosen according to the hierarchies previously described. Where the RoB2 guidance did not cover specific situations found in this review, decision rules were developed and applied in a standardised manner (Appendix B). The RoB2 assessment was completed in full by CPC with $18 \%(n=2)$ undertaken independently by ML. The same previously described strategy for addressing disagreements was followed. Authors were contacted to request clarifications or to access missing data and given a two-week period to reply.

A narrative synthesis based on the Economic and Social Research Council (ESRC) Methods Programme was planned [69]. Meta-analysis was not appropriate due to all studies being at high risk of bias for the outcomes of interest, with most having high or some concerns regarding missing data, alongside the substantial clinical heterogeneity. Since meta-analysis was judged to be inappropriate, a harvest plot using vote counting, based on direction of effect, was used with categorisation of the studies by their effect (detrimental, no or beneficial effect) [40]. Effect size or statistical significance were not included for this categorisation as this can be misleading [40]. Vote counting was used for both the primary and secondary outcomes using mean change score for one comparator and one time-point according to the hierarchy previously described. If the outcomes were measured immediately after the intervention, as well as, at an additional time with a stressor, the former was only included for the vote counting. A set of decision criteria were created for interventions with a stressor and those without to standardise interpretation of the expected response to the intervention (Appendix B).

The quality and relevance of evidence was appraised using the 'Weight of Evidence' approach [70] and described in the guidance on narrative synthesis for the ESRC guid- 
ance [69]. In accordance with the ESRC guidance, trustworthiness was measured by Jadad's scale $[69,71]$.

\section{Results}

\subsection{Study Selection}

Eleven articles, describing eleven studies, met the inclusion criteria. The PRISMA flowchart is displayed in Figure 1. Ten studies were journal articles and therefore classed as published literature $[35,37,72-79]$. One study was a dissertation for partial fulfilment of $\mathrm{PhD}$ and classed as grey literature [80]. All 11 studies were individually randomised parallel-group trials. Of these, three were described as pilot or exploratory studies but nonetheless presented data on interventions' effectiveness $[37,75,80]$. The excluded full text published studies (with reasons) are listed in Appendix C.

Records identified through database searching $(n=7999)$
Additional records identified

through grey literature

( $n=37$ advanced Google search)
Records excluded 1st reviewer $(n=5320)$ Then records excluded by $1^{\text {st }}$ and $2^{\text {nd }}$ reviewer $(n=796)$

Full-text articles excluded with reasons $(n=122)$ : wrong population $n=9$ wrong intervention $n=15$

no comparator $n=2$ wrong outcome $n=22$ wrong study design $=61$

$\frac{7}{\frac{d}{0}}$

$$
\begin{aligned}
& \text { Full-text articles assessed } \\
& \text { for eligibility } \\
& (n=132) \\
& \text { Studies included in } \\
& \text { narrative synthesis \& } \\
& \text { harvest plot } \\
& (n=10)
\end{aligned}
$$

Studies included in narrative synthesis \& harvest plot ( $n=11$ );

Studies included in metaanalysis
$(\mathrm{n}=0)$

$$
\begin{aligned}
& \text { Cited by } \\
& n=1 \text { to be included } \\
& \text { Reference searches } \\
& n=0 \text { to be included } \\
& \text { Identified by key authors } \\
& n=0 \text { to be included }
\end{aligned}
$$

Figure 1. Adapted preferred reporting items for systematic reviews and meta-analysis (PRISMA) diagram adapted from Moher et al. [39]; * other included not available due to COVID-19 ( $n=2)$, did not meet criteria for requesting inter-library loan $(n=10) \&$ ongoing trial $(n=1)$.

\subsection{Study Characteristics}

Six studies were conducted in USA $[72,75-77,79,80]$, three in Canada $[35,73,78]$, one in Scotland [37], and one in Austria [74]. Sample sizes (for those randomised) across all included studies varied from 20 to 357 students.

\subsubsection{Population}

For the majority (9 studies), the participants were university students [35,37,72,73,76-80]. Seven studies reported the characteristics according to the recruited sample size $[35,37,72,73,76,77,80]$ and three for the analysed sample size $[74,78,79]$; one reported the characteristics of the students attending the degree programme from which the participants were recruited and not the sample's characteristics (this study is excluded from the descriptive statistics below) [75]. Ten studies reported gender with the majority (ranging from 57\% 
to $85 \%$ ) of participants being female $[35,37,72-74,76-80]$. The most common age bracket was 20 -year-olds and under, followed by 21 to 25 -year-olds. Type of student was clearly reported in five studies $[35,73,76,77,79]$. Of those, $80 \%$ were undergraduates $[35,73,76,77]$. The students' year of academic studies was fully reported in two studies [35,74]. Five studies reported ethnicity $[35,73,76,77,80]$. None of the studies reported health status or socio-economic status (SES). The participants studied a range of course subjects (such as psychology and nursing). Three studies collected the potential confounder of pet ownership $[37,72,78]$, and one reported experience with the animals employed in the intervention (horses) [80].

\subsubsection{Intervention}

Ten studies employed dogs [35,37,72-79] and one employed horses [80]. Group sessions were the most common format: seven studies implemented this session type [35,37,72,74,76-78], whilst two implemented individual sessions [73,80]. A further two studies implemented either a combination of group and individual sessions [75] or the format of sessions was not clearly reported [79]. The student to dog ratio in the group sessions was clearly reported in two studies [35,37] and implied in three [74,76,77], ranging from 3 to 4 -students-per-dog to 12 to 14 -students-per-dog.

The presence of a handler during the sessions was clearly reported in seven studies $[35,37,72,74,78-80]$. Nine studies allowed free interaction with the animals $[35,37,72,73,75-79]$ and two used a structured format $[74,80]$. Most interventions $(n=8)$ corresponded to the definition of AAA described in $3.3[37,72,73,75-79]$. Two studies were classified as AAT $[35,74]$ and one combined AAT and AAE together [80]. These classifications were mostly from an objective assessment of the description provided vis-à-vis the definitions outlined in 3.3. If insufficient detail for an objective assessment, the classification used by the primary authors was kept [35]. Length of intervention ranged from unspecified to $90 \mathrm{~min}$, with the modal length being between 10 to $20 \mathrm{~min}$. Seven studies used a single session [35,37,72,73,78-80]. Four studies used multiple sessions [74-77]; of these, two used once-weekly sessions for four weeks [76,77]; one implemented three sessions with non-reporting of the time interval between sessions [74]; and one allowed various lengths and frequencies over a 15 to 16-week period at the participant's choice [75]. None of the studies reported monitoring or measuring the intervention's fidelity. The theoretical frameworks were clearly stated in three studies $[35,37,80]$. More information regarding the theoretical frameworks is included in Appendix D.

\subsubsection{Outcomes}

The primary outcomes were self-reported anxiety and stress measured before and after the intervention. Seven studies measured self-reported anxiety $[37,74-77,79,80]$ with most using the State-Trait Anxiety Inventory (STAI), apart from one study which used the Hospital Anxiety and Depression Scale (HADS) [75]. Two studies measured stress using the Perceived Stress Scale (PSS) on the original 5-point Likert scale [35,78].

Regarding the secondary outcomes, two studies measured depression $[75,77]$ using the HADS-depression subscale and Beck Depression Inventory II (BDI II), respectively. Five studies measured mood/affect, with most using Positive and Negative Affect Schedule (PANAS) $[72,73,76,78]$ and one used the University of Wales Institute of Science and Technology Mood Adjective Checklist (UMACL) [37]. Well-being was measured in three studies $[35,37,78]$ using various tools.

The timing of outcome measurement after the intervention varied substantially between studies (with some reporting multiple time-points outlined in Table 2) and encompassed: immediately after the intervention without a stressor $(n=6)$; after the intervention but before an exam $(n=2)$; after the intervention and an experimental stressor $(n=4)$; within $24 \mathrm{~h}$ of the intervention $(n=1)$; 2 weeks after the intervention $(n=1)$; up to 1 month after the intervention $(n=1)$; up to $15-16$ weeks since the start of the intervention $(n=1)$. 
Table 2. Characteristics of included studies ordered alphabetically with relevant outcome measures $(\mathrm{NR}=$ not reported; $\mathrm{SD}=$ standard deviation).

\begin{tabular}{|c|c|c|c|c|c|c|c|}
\hline \multirow[b]{2}{*}{$\begin{array}{l}\text { First Author, } \\
\text { Year \& Country }\end{array}$} & \multirow{2}{*}{$\begin{array}{c}\text { Participants } \\
\text { Characteristics }\end{array}$} & \multicolumn{3}{|c|}{ Intervention } & \multirow[b]{2}{*}{ Comparator } & \multicolumn{2}{|c|}{ Outcomes } \\
\hline & & $\begin{array}{c}\text { Theoretical Framework } \\
\text { Articulated }\end{array}$ & Description of Intervention & $\begin{array}{l}\text { Type of AAI } \\
\text { \& Delivery }\end{array}$ & & Tools Used & Time-Points \\
\hline $\begin{array}{l}\text { Banks [72] } \\
2018 \\
\text { USA }\end{array}$ & $\begin{array}{l}\text { University students with } \\
\text { some recruited from } \\
\text { psychology department } \\
\text { (76.8\% female) } \\
\text { Mean age 20.05 (SD 3.38) } \\
\text { Year of study, type of } \\
\text { graduate, ethnicity, health } \\
\text { status or SES NR }\end{array}$ & No & $\begin{array}{l}\text { Group (free interaction) with } \\
\text { as many dogs as wanted } \\
\text { (student: dog ratio NR) for } \\
10 \text { min single session during } \\
\text { mid-term exam week } \\
\text { Various breeds (e.g., Beagle, } \\
\text { Golden Retrievers, } \\
\text { German Shepherds) } \\
\end{array}$ & $\begin{array}{l}\text { AAA } \\
\text { Handler }\end{array}$ & $\begin{array}{l}\text { No-treatment } \\
\text { control }\end{array}$ & $\begin{array}{l}\text { PANAS-positive } \\
\text { \& negative }\end{array}$ & $\begin{array}{l}\text { Pre \& post stressor } \\
\text { (SART \& letter/ } \\
\text { pattern comparison) }\end{array}$ \\
\hline $\begin{array}{c}\text { Fiocco [73] } \\
2017 \\
\text { Canada }\end{array}$ & $\begin{array}{c}\text { Undergraduate university } \\
\text { students } \\
\text { (77.1\% female) } \\
\text { Mean age 21.02 (SD 5.5) } \\
\text { Ethnicity: } 37.7 \% \text { Caucasian; } \\
\text { 8.2\% Black/ African } \\
\text { American; } 54.1 \% \text { Other } \\
\text { Year of study, health status or } \\
\text { SES NR } \\
\end{array}$ & Partial & $\begin{array}{l}\text { Individual (free interaction as } \\
\text { long as participant remained } \\
\text { seated) with a dog for } 10 \text { min } \\
\text { single session } \\
\text { Various breeds of different } \\
\text { ages \& sizes/breed (e.g., Irish } \\
\text { Setter, Schnoodle, } \\
\text { Greyhound, King Charles } \\
\text { Spaniel) }\end{array}$ & $\begin{array}{l}\text { AAA } \\
\text { Unclear if handler } \\
\text { present }\end{array}$ & $\begin{array}{l}\text { No-treatment control } \\
\text { (sitting for } 10 \mathrm{~min} \text { ) }\end{array}$ & $\begin{array}{l}\text { PANAS-positive } \\
\text { \& negative }\end{array}$ & $\begin{array}{l}\text { Pre, post AAA \& then } \\
\text { after stressor (PASAT) }\end{array}$ \\
\hline $\begin{array}{c}\text { Gebhart [74] } \\
2019 \\
\text { Austria }\end{array}$ & $\begin{array}{l}\text { First-year students at } \\
\text { nursing school } \\
\quad(77 \% \text { female) } \\
\text { Median age 20 (IQR 19-22) } \\
\text { Type of graduate not clearly } \\
\text { specified; health status, } \\
\text { ethnicity or SES NR }\end{array}$ & Partial & $\begin{array}{l}\text { Group interaction (structured } \\
\text { with different tasks, playing } \\
\& \text { interacting with dogs) } \\
\text { student: dog/handler ratio } \\
\text { implied } 3 \text { students: } 1 \text { therapy } \\
\text { dogs /handler for } 45-60 \text { min } \\
\text { for } 3 \text { sessions (time interval } \\
\text { between sessions NR) }\end{array}$ & $\begin{array}{l}\text { AAT } \\
\text { Handler }\end{array}$ & $\begin{array}{l}\text { No-treatment control } \\
\text { unstructured free hour; } \\
\text { music therapy (body } \\
\text { percussion) \& } \\
\text { mandala painting }\end{array}$ & STAI-S & $\begin{array}{l}\text { Pre \& post normal day } \\
\text { Pre \& post exam day }\end{array}$ \\
\hline $\begin{array}{l}\text { Grajfoner [37] } \\
\text { 2017 } \\
\text { Scotland }\end{array}$ & $\begin{array}{l}\text { University students } \\
\text { (64.4.\% female) } \\
\text { Mean age 21.6 (SD 3.4) } \\
\text { Year of study, type of } \\
\text { graduate, health status, } \\
\text { ethnicity or SES NR }\end{array}$ & Yes & $\begin{array}{l}\text { Group (free interaction) } \\
\sim 6 \text { students: } 1 \text { dog/handler } \\
\text { ratio for } 20 \text { min single session } \\
\text { Various breeds (e.g., } \\
\text { Labrador, Lhasa Apso, } \\
\text { Golden Retriever) }\end{array}$ & $\begin{array}{l}\text { AAA } \\
\text { Handler }\end{array}$ & $\begin{array}{c}\text { Handler only (HO) } \\
\text { \& dog only (DO) } \\
\text { (handler present; no } \\
\text { interaction) }\end{array}$ & $\begin{array}{c}\text { STAI } \\
\text { WEMWBS } \\
\text { UMACL }\end{array}$ & Pre \& post \\
\hline
\end{tabular}


Table 2. Cont.

\begin{tabular}{|c|c|c|c|c|c|c|c|}
\hline \multirow[b]{2}{*}{$\begin{array}{l}\text { First Author, } \\
\text { Year \& Country }\end{array}$} & \multirow{2}{*}{$\begin{array}{c}\text { Participants } \\
\text { Characteristics }\end{array}$} & \multicolumn{3}{|c|}{ Intervention } & \multirow[b]{2}{*}{ Comparator } & \multicolumn{2}{|c|}{ Outcomes } \\
\hline & & $\begin{array}{l}\text { Theoretical Framework } \\
\text { Articulated }\end{array}$ & Description of Intervention & $\begin{array}{l}\text { Type of AAI } \\
\text { \& Delivery }\end{array}$ & & Tools Used & Time-Points \\
\hline $\begin{array}{l}\text { Hall [75] } \\
2018 \\
\text { USA }\end{array}$ & $\begin{array}{l}\text { Level } 2 \text { community college } \\
\text { associate degree nursing } \\
\text { programme } \\
\text { Gender, age, year of study, } \\
\text { type of graduate or health } \\
\text { status, ethnicity or SES NR } \\
\text { (only demographics of } \\
\text { the course) }\end{array}$ & Partial & $\begin{array}{l}\text { Mix of group or individual } \\
\text { session (free interaction) with } \\
\text { numerous opportunities to } \\
\text { interact with dog. Dog on } \\
\text { campus minimum twice a } \\
\text { week, visited students at } \\
\text { various locations \& on exam } \\
\text { days for } 30 \text { min pre-exams. } \\
\text { Intensity, length \& frequency } \\
\text { of sessions NR } \\
\text { Standard Poodle }\end{array}$ & $\begin{array}{c}\text { AAA } \\
\begin{array}{c}\text { Handler (unclear if } \\
\text { always present) }\end{array}\end{array}$ & No-treatment control & $\begin{array}{l}\text { HADs-anxiety } \\
\text { \& depression }\end{array}$ & $\begin{array}{l}\text { Pre \& post (which is } \\
\text { after } 15-16 \text { weeks from } \\
\text { start of intervention) }\end{array}$ \\
\hline $\begin{array}{c}\text { Hunt [76] } \\
2018 \\
\text { USA }\end{array}$ & $\begin{array}{c}\text { Undergraduate students } \\
\text { enrolled in psychology } \\
\text { courses (74\% female) } \\
\text { Mean age 19.3 (SD NR) \& } \\
\geq 18 \text { yrs old } \\
\text { Ethnicity: 52\% non-Hispanic } \\
\text { White; } 27 \% \\
\text { Asian/Asian-American; } 9 \% \\
\text { Hispanic/Latino; 5\% } \\
\text { Black/African American, 4\% } \\
\text { Multiracial, 2\% Indian; 1\% } \\
\text { Arab } \\
\text { Year of study, health status or } \\
\text { SEES NR }\end{array}$ & Partial & $\begin{array}{l}\text { Group interaction (free } \\
\text { interaction) with a dog plus } \\
\text { interactive games, } \\
\text { icebreakers \& snacks } \\
\text { student: dog ratio not clearly } \\
\text { stated but implied } 12-14 \\
\text { students: } 1 \text { dog of unclear } \\
\text { length for once/week for } \\
4 \text { sessions } \\
\text { Golden Retriever }\end{array}$ & $\begin{array}{c}\text { AAA } \\
\text { Unclear if } \\
\text { handler present }\end{array}$ & $\begin{array}{l}\text { No-treatment control; } \\
\text { mindfulness training } \\
\text { alone; yoga alone; } \\
\text { or mindfulness } \\
\text { training with yoga }\end{array}$ & $\begin{array}{l}\text { STAI-S } \\
\text { PANAS-positive } \\
\text { \& negative }\end{array}$ & $\begin{array}{l}\text { Pre \& post every } \\
\text { session \& once } \\
1-3 \text { weeks after } \\
\text { completion of AAA } \\
\text { with stressor } \\
\text { (WAIS-IV IQ test) }\end{array}$ \\
\hline $\begin{array}{l}\text { Meola [80] } \\
2017 \\
\text { USA }\end{array}$ & $\begin{array}{l}\text { University students enrolled } \\
\text { on accredited counselling } \\
\text { program (85\% female) } \\
\text { Mean age 30.8 (SD NR) } \\
\text { Ethnicity: 85.7\% Caucasian; } \\
\text { 9.5\% African American } \\
\text { Year of study, type of } \\
\text { graduate (some Masters \& } \\
\text { PhD but NR for all), health } \\
\text { status, or SES NR }\end{array}$ & Yes & $\begin{array}{l}\text { Individual (structured \& } \\
\text { tailored) equine-assisted } \\
\text { learning supervision (EALS) } \\
\text { session with a horse with } 3 \\
\text { different activities: for 1-h } \\
\text { single session }\end{array}$ & $\begin{array}{c}\text { AAT/AAE } \\
\text { Handler (who was also } \\
\text { an instructor/ } \\
\text { facilitator) }\end{array}$ & No-treatment control & STAI-S & $\begin{array}{l}\text { Pre \& then post up to } \\
\text { one month after } \\
\text { intervention }\end{array}$ \\
\hline $\begin{array}{c}\text { Shearer [77] } \\
2016 \\
\text { USA }\end{array}$ & $\begin{array}{c}\text { Undergraduate university } \\
\text { students in psychology } \\
\text { courses (57\% female) } \\
\text { Ethnicity: } 43 \% \text { Asian; } 41 \% \\
\text { Caucasian; } 7 \% \text { Hispanic; } 3 \% \\
\text { African American; } 3 \% \text { Other; } \\
1 \% \text { Native American; } 1 \% \\
\text { Pacific Islander; } 1 \% \\
\text { unidentified. } \\
\text { Year of study, health status, } \\
\text { age or SES NR }\end{array}$ & Partial & $\begin{array}{c}\text { Group session (free } \\
\text { interaction) with a dog plus } \\
\text { games \& snacks } \\
\text { students: dog ratio not clearly } \\
\text { specified but implied 12-13 } \\
\text { students: } 1 \text { dog for } 1 \mathrm{~h} / \text { week } \\
\text { for } 4 \text { weeks }\end{array}$ & $\begin{array}{c}\text { AAA } \\
\text { Facilitator }\end{array}$ & $\begin{array}{l}\text { No-treatment control } \\
\text { (added in 2nd phase) } \\
\text { or } \\
\text { mindfulness } \\
\text { meditation }\end{array}$ & $\begin{array}{l}\text { STAI-S } \\
\text { BDI II }\end{array}$ & $\begin{array}{l}\text { Pre \& then post each } \\
\text { session for } 4 \text { weeks \& } \\
\text { then once } \\
\text { 1-2 weeks after } \\
\text { completion of AAA } \\
\text { with stressor } \\
\text { (WAIS-IV) }\end{array}$ \\
\hline
\end{tabular}


Table 2. Cont.

\begin{tabular}{|c|c|c|c|c|c|c|c|}
\hline \multirow[b]{2}{*}{$\begin{array}{l}\text { First Author, } \\
\text { Year \& Country }\end{array}$} & \multirow{2}{*}{$\begin{array}{c}\text { Participants } \\
\text { Characteristics }\end{array}$} & \multicolumn{3}{|c|}{ Intervention } & \multirow[b]{2}{*}{ Comparator } & \multicolumn{2}{|c|}{ Outcomes } \\
\hline & & $\begin{array}{l}\text { Theoretical Framework } \\
\text { Articulated }\end{array}$ & Description of Intervention & $\begin{array}{l}\text { Type of AAI } \\
\& \text { Delivery }\end{array}$ & & Tools Used & Time-Points \\
\hline $\begin{array}{c}\text { Ward-Griffin [78] } \\
2018 \\
\text { Canada }\end{array}$ & $\begin{array}{l}\text { University students enrolled } \\
\text { in introductory psychology } \\
\text { classes (78\% female) } \\
\text { Mean age 19.4 (SD 3.73) } \\
45.5 \% \text { first-year students; } \\
\text { others NR } \\
\text { Type of graduate, health } \\
\text { status, ethnicity or SES NR }\end{array}$ & Partial & $\begin{array}{l}\text { Group session (free } \\
\text { interaction) with dogs. } \\
\text { student to dog ratio not } \\
\text { clearly specified with 7-12 } \\
\text { dogs present with handlers } \\
\text { for up to } 90 \text { min single } \\
\text { session during mid-term } \\
\text { exam season (on average } \\
\text { participants spent } 30 \text { min in } \\
\text { the space) }\end{array}$ & $\begin{array}{l}\text { AAA } \\
\text { Handler }\end{array}$ & Wait-list control & $\begin{array}{c}\text { PSS } \\
\text { PANAS-positive \& } \\
\text { negative } \\
\text { SWLS } \\
\text { Subjective Happiness } \\
\text { Scale } \\
\text { Medical Outcomes } \\
\text { Study Social Support } \\
\text { Scale }\end{array}$ & $\begin{array}{l}\text { Pre \& within } 24 \mathrm{~h} \\
\text { of AAA }\end{array}$ \\
\hline $\begin{array}{l}\text { Williams [79] } \\
2018 \\
\text { USA }\end{array}$ & $\begin{array}{l}\text { University graduate students } \\
\text { in pharmacy/physical } \\
\text { therapy (63.2\% female) } \\
\text { Mean age 24.42 (SD NR) } \\
\text { Year of study, health status, } \\
\text { ethnicity, or SES NR }\end{array}$ & Partial & $\begin{array}{l}\text { Not clearly specified but } \\
\text { inferred as individual free } \\
\text { interaction (as long as no } \\
\text { active running \& playing) } \\
\text { with a dog for } 12 \text { min single } \\
\text { session prior to exam }\end{array}$ & $\begin{array}{l}\text { AAA } \\
\text { Handler }\end{array}$ & $\begin{array}{l}\text { No-treatment control } \\
\text { ("business as usual" } \\
\text { control = quiet time } \\
\text { studying) }\end{array}$ & STAI-S \& T & $\begin{array}{l}\text { Pre \& post (but before } \\
\text { an exam) }\end{array}$ \\
\hline
\end{tabular}

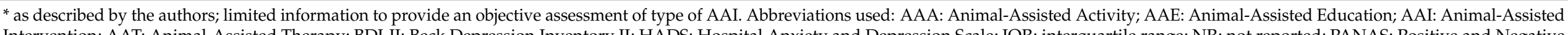

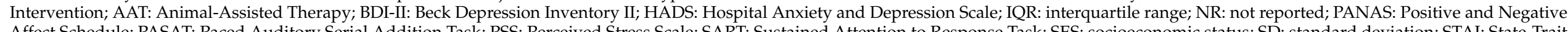

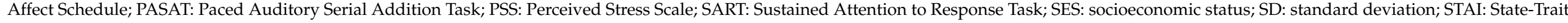

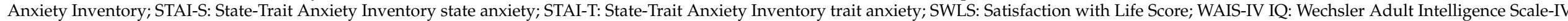


Regarding adverse events reporting, Hall [75] described ten individuals who reported increased anxiety and stress due to being in the control group and unable to participate with the animal. These participants were subsequently removed from the study to allow interaction. No other adverse events were reported. None of the studies specifically reported any adverse events for the animals involved.

Characteristics are summarised in Table 2.

\subsection{Risk of Bias Assessment}

Figure 2 summarises the risk of bias for each domain with an overall assessment for each study for all the relevant outcomes. All studies were at overall high risk of bias for the outcomes of interest as susceptible to high risk of bias in the domain "measurement of the outcome". This was mainly due to the nature of the intervention as participants could not be blinded and the measures were self-reported, therefore were not objective.

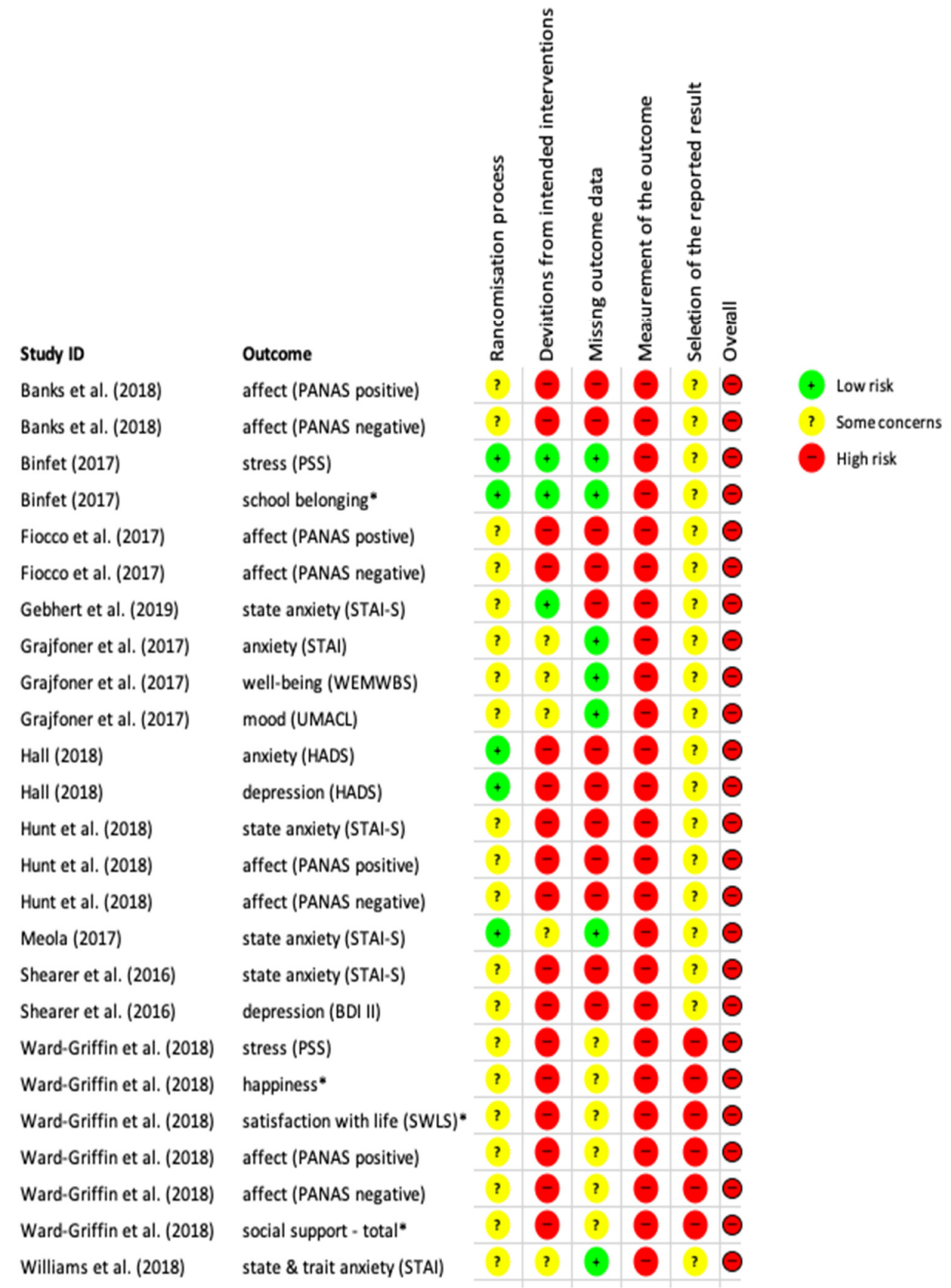

Figure 2. Risk of bias assessment (RoB2 assessment) for all included studies on the outcomes of interest; ${ }^{*}$ considered as a proxy for well-being. 


\subsection{Strength of Evidence}

The quality and relevance of evidence was appraised using the 'Weight of Evidence' approach [70] and described in the guidance on narrative synthesis for the ESRC guidance [69]. The strength of evidence of the included studies is summarised in Table 3. One study had high overall weight [74], eight $[35,37,73,75,76,78-80]$ had medium overall weight and two had low overall weight $[72,77]$.

Table 3. The strength of evidence for the included studies in accordance with the 'Weight of Evidence' approach [70].

\begin{tabular}{|c|c|c|c|c|}
\hline Study & $\begin{array}{l}\text { Trustworthiness } \\
\text { (A) }\end{array}$ & $\begin{array}{l}\text { Appropriateness } \\
\text { (B) }\end{array}$ & $\begin{array}{l}\text { Relevance } \\
\text { (C) }\end{array}$ & $\begin{array}{l}\text { Overall Weight } \\
\text { (D) }\end{array}$ \\
\hline Banks et al. [72] & Low & High & High & Low \\
\hline Binfet [35] & Medium & High & High & Medium \\
\hline Fiocco et al. [73] & Medium & High & High & Medium \\
\hline Gebhart et al. [74] & High & High & High & High \\
\hline Grajfoner et al. [37] & Medium & High & High & Medium \\
\hline Hall [75] & Medium & High & High & Medium \\
\hline Hunt et al. [76] & Medium & High & High & Medium \\
\hline Meola [80] & Medium & High & High & Medium \\
\hline Shearer et al. [77] & Low & High & High & Low \\
\hline Ward-Griffin et al. [78] & Medium & High & High & Medium \\
\hline Williams et al. [79] & Medium & High & High & Medium \\
\hline
\end{tabular}

\subsection{Narrative Synthesis: Interventions' Effect}

As all the studies were at high risk of bias for the outcomes of interest, with most having high or some concerns regarding missing data, alongside the substantial clinical heterogeneity, a meta-analysis was not appropriate as it was unlikely to provide meaningful results.

All the included measurement scales provided continuous data; results were presented in various formats such as pre- and post-values, mean change or adjusted estimates of the intervention's effects (for example, using analysis of covariance (ANCOVA) with baseline measurements included as a covariate). Appendix D provides a summary of the studies' results with mean change (post-scores minus pre-scores) as the common parameter using the most immediate measurement of outcomes after the intervention (or the next best alternative).

\subsubsection{Primary Outcomes: Anxiety}

Seven studies reported the intervention's effect on self-reported anxiety levels $[37,74-77,79,80]$. Six studies employed dogs $[37,74-77,79]$ and one employed horses [80]. Four studies used group sessions [37,74,76,77], one used individual sessions [80], one offered both group and individual sessions [75] and one did not explicitly state the type of sessions but was inferred to be individual [79]. Session length varied and included student's choice to sessions lasting 12, 20 and up to $60 \mathrm{~min}$. Three studies offered a single session $[37,79,80]$, two offered four sessions (once/week) [76,77], one varied depending on students' choice [75] and one offered three consecutive sessions but did not report the time interval between sessions [74]. Most interventions were consistent with AAA [37,75-77,79] and of these studies $(n=5)$, two included, alongside the dogs, interactive games, icebreakers and snacks for the participants/dogs [76,77]. Furthermore, Gebhart et al. [74] offered AAT and Meola [80] offered tailored and structured individual sessions called equine-assisted learning supervision (EALS). The latter incorporated both educational and therapeutic goals, therefore combining $\mathrm{AAE}$ and AAT. 
Six studies tested outcomes without a stressor, with four showing a statistically significant improvement in favour of the AAI $[37,74,75,77]$. Four studies tested the outcomes immediately after the intervention without a stressor, with three showing a statistically significant reduction in favour of the AAI $[37,74,77]$ and one showing a non-statistically significant reduction but did not include a power calculation [76]. For the two studies which tested the outcome after a longer time interval, Meola [80] found a non-statistically significant reduction in anxiety when measured up to one month after the intervention but this study was under-powered. Hall [75] found a statistically significant reduction in the post-intervention scores 15-16 weeks after the intervention had started.

Four studies involved a stressor: two assessed the outcomes after the intervention but prior to an exam $[74,79]$ and two assessed the outcomes after an experimental cognitive test (WAIS-IV IQ test) which was designed to imitate evaluative testing that occurs in higher education [76,77]. Two studies found no statistical difference [74,77] but a power calculation was not included. Hunt et al. [76], despite no significant effect of condition on anxiety after a stressor, still undertook paired comparisons which showed a statistically significant higher level of anxiety in the AAI group compared to the control group. Williams et al. [79] showed an increase in anxiety for both groups, after the intervention but before an exam, which one might therefore expect. However, the control group had statistically higher anxiety levels than the AAI group.

Overall risk of bias was high for all seven studies regarding the outcomes of interest. Regarding overall strength of evidence, one study had high [74], one had low [77] and the remaining five had medium strength. Using vote counting, according to direction of effect and not statistical significance as described in the methods, all seven studies showed a beneficial effect in favour of the intervention compared to the comparator (demonstrated in harvest plot in Figure 3).

\subsubsection{Primary Outcome: Stress}

Two studies, using single group sessions with dogs, measured self-reported stress $[35,78]$. Binfet [35] described the intervention as AAT whilst the intervention in Ward-Griffin et al. [78] was consistent with AAA. The sessions lasted varying amounts of time from $20 \mathrm{~min}$ [35] to up to $90 \mathrm{~min}$ (but on average $30 \mathrm{~min}$ ) [78]. Neither study used a stressor but one study [78] occurred during mid-term exam season. Despite the differences between the two studies, both showed a statistically significant reduction in stress when measured within $24 \mathrm{~h}$ of the intervention. This effect was not sustained at the two-week follow-up for the one study that included longer follow-up [35]. Therefore, these studies showed cautious preliminary evidence of a short-term, statistically significant, beneficial effect on stress, using AAIs, with students at Canadian universities. However, with such a small number of studies (with both being at high risk of bias for the outcomes of interest), caution is needed regarding generalisability to other countries and settings.

\subsubsection{Secondary Outcomes: Depression, Mood/Affect and Well-Being}

The evidence for depression is only based on two studies with different study characteristics and with mixed results $[75,77]$. One study, with low strength of evidence, showed a non-statistically significant beneficial effect on depression (with a stressor) [77] but we are unable to state if this is the true effect as the study could have been underpowered. The other study showed a reduction in depression scores for both intervention and comparator but by a larger degree for the control (without a stressor) [75]. However, caution is required due to the data's distribution (skewed) and how the results were provided (mean) personal communication [81].

The evidence for mood is mixed with five studies measuring this outcome $[37,72,73,76,78]$. A non-statistically significant detrimental effect appeared to occur particularly when a stressor is applied. Of the two studies that showed statistically significant beneficial results without a stressor, this result had not lasted by the 4th session for one study. Where a non-statistical significance was shown, a power calculation was not 
included. Therefore, the studies may have been underpowered to demonstrate the true effect (which may or may not be similar to the results explored here). Further investigation is required before any conclusions can be made for this outcome.

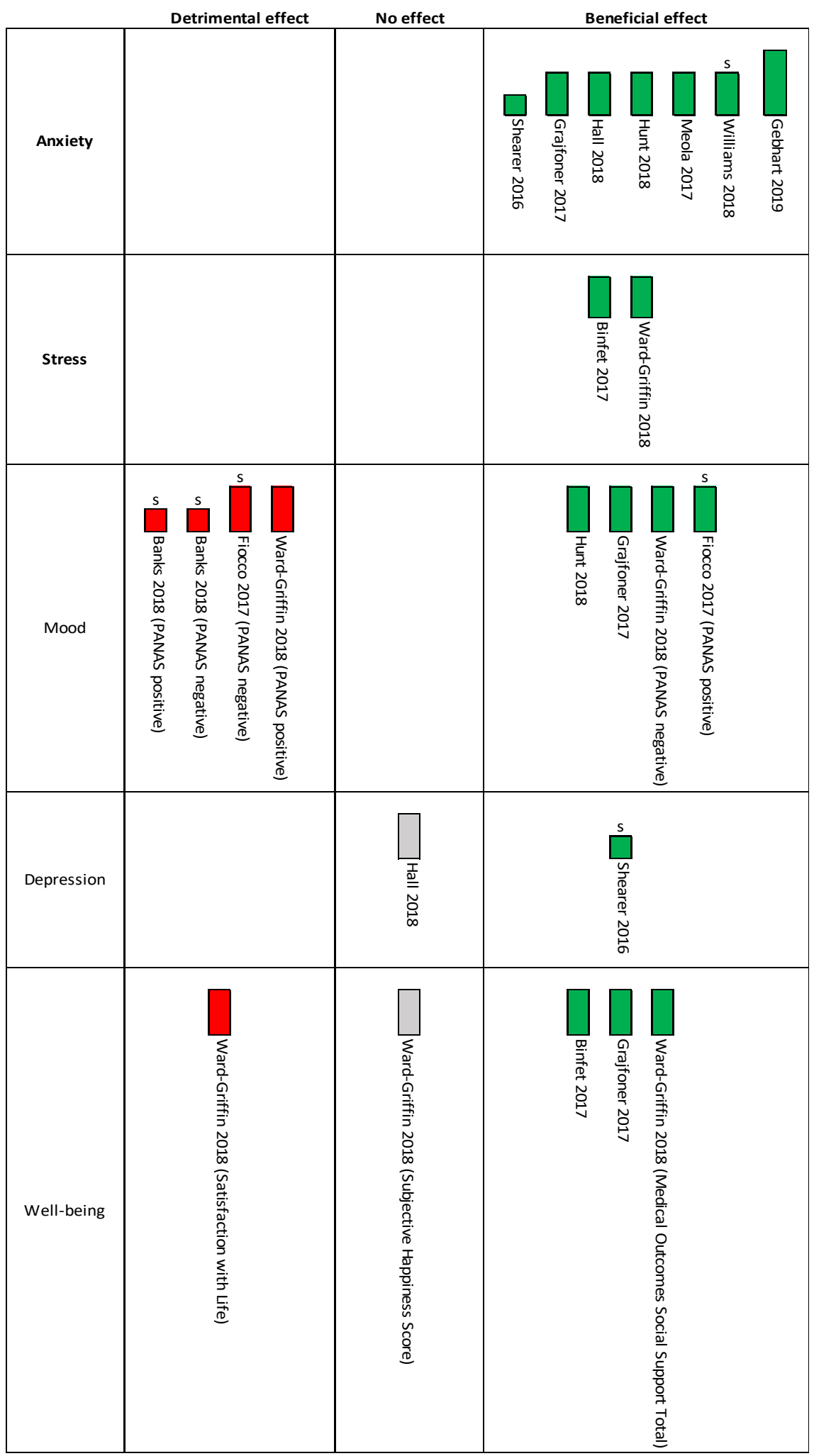

Figure 3. Harvest plot for the primary \& secondary outcomes for one comparator \& one time-point as described in the methods. s stands for stressor; height of bars relate to overall strength of evidence $($ tallest $=$ high; shortest $=$ low $)$. 
Three studies measured well-being using various tools (for example, Sense of Belonging in School, Warwick-Edinburgh Mental Well-being Scale (WEMWBS), Satisfaction with Life Scale (SWLS), Subjective Happiness Scale and Medical Outcomes Study Social Support) $[35,37,78]$. Overall, tentative but mostly beneficial effects were found in varying measures of well-being when measured immediately after or within $24 \mathrm{~h}$ of the AAI. Where a non-statistically significant effect was found, the outcomes were measured within $24 \mathrm{~h}$ of the intervention during mid-term exam season. Additionally, no power calculation had been included for the non-statistically significant findings, and therefore, distinguishing between true "no effect" or being underpowered was not possible.

\section{Discussion}

\subsection{Statement of Principal Findings}

This systematic review included 11 RCT assessing AAIs on mental health outcomes for students attending higher education in a variety of settings and countries. The evidence suggests that AAIs could provide short-term beneficial results for anxiety in students attending higher education. There is limited evidence for stress, and inconclusive evidence for depression, well-being and mood. These results are from studies at high risk of bias for the outcomes of interest with mostly medium strength of evidence.

\subsection{Strengths and Weaknesses of the Review}

The strengths of this review include a comprehensive search strategy incorporating both grey and published literature. Additionally, independent conduct of screening, data extraction and risk of bias with inclusion of a third reviewer to resolve any discrepancies were incorporated. This reduced the introduction of random and systematic errors [82]. Development of decision rules, where required, increased transparency and rigor. Furthermore, this review combined RCTs, which represent the gold standard study design for evaluating a causal relationship and for measuring an intervention's effectiveness [83]. A meta-analysis was not appropriate for reasons already described; therefore, vote counting, based on direction of effect and not statistical significance, was employed. Vote counting using statistical significance can be misleading especially in studies where no power calculation was reported and no significance was found [40]. The lack of statistically significant effect may either be due to the study being underpowered or may reflect a true lack of effect [40]. However, when using vote counting on direction of effect without considering statistical significance, the effect seen may be due to chance. Additionally, vote counting methods are unable to provide a precise estimate of the overall effect size.

Due to COVID-19, some resources were inaccessible (list included in Appendix C). Additionally, a pragmatic approach to the Advanced Google search was incorporated using only primary outcomes. Well-being is a particularly broad concept. Proxies that were strongly related to well-being were included but may not have been an exhaustive list. Therefore, some articles that could have met the eligibility criteria may have been missed. A percentage above a minimum for double screening, data extraction and risk of bias assessment was chosen due to resource and time constraints, which represents a limitation. Using the strength of evidence approach, overall weight was influenced mainly by how well the authors described randomisation and/or presence of withdrawals/missing data as all the studies were relevant RCTs where double blinding was difficult. Where not reported, concluding whether these elements simply had not occurred or had occurred but not described due to reasons (such as word-count limits) was impossible, unless clarified by the authors through correspondence. Furthermore, different tools to assess strength of evidence or risk of bias may have produced different findings.

\subsection{Strengths and Weaknesses of the Studies}

The limitations of the primary evidence reviewed included variable levels of descriptive reporting in the included studies, such as participant characteristics, delivery of the intervention and theory of change. For example, the descriptions of the included AAIs 
varied considerably from a high level of detail to only a single sentence or short paragraph. Therefore, providing conclusions about whether certain types of AAIs were more effective that others or to isolate the "active ingredient" of effective AAIs was not possible. Most of the participants were females, ranging from $57 \%$ to $85 \%$, and authors rarely commented on how well the sample population represented the target population. Furthermore, all the participants volunteered to participate and, therefore, may not be representative of the target population [84]. For example, those volunteering (and therefore, self-selecting) may be more motivated and/or have a different mental health status than those who did not $[84,85]$. Additionally, individuals who are afraid, allergic or have a medical condition precluding participation with animals are unlikely to have volunteered. Therefore, building a comprehensive picture of the type of individual attending higher education, who would benefit from AAIs was challenging. These reporting issues meant that assessing the generalisability of the results was also problematic.

The outcomes reviewed were self-reported and can be subject to unconscious and/or conscious ascertainment bias. With this type of intervention, blinding of participants or individuals delivering the intervention was difficult, if not impossible. This resulted in all the studies having an overall high risk of bias for the outcomes of interest for this systematic review. Additionally, participant expectancy bias could have been introduced, which was highlighted in Williams et al. [79] as $90 \%$ of the control group sampled $(n=15)$ stated they thought an interaction with the dog would have reduced their stress prior to an exam. Despite these limitations, capturing how an individual feels after an intervention/comparator is important. To aid corroboration and confidence with self-reported results, triangulation would be beneficial such as with objective measures (for example, physiological outcomes) and/or blinded behavioural observations [86]. Indeed, some of the studies reported physiological outcomes but were beyond the scope of this systematic review, which is a limitation.

Furthermore, for the outcomes where no statistical difference was found, either no power calculation was included, or the study was underpowered. In those studies, no definitive conclusion can be derived about the effectiveness of that particular intervention for that specific outcome as it is not possible to state if the non-statistically significant difference was the true effect or not [87].

\subsection{Study Meaning: Possible Mechanism and Implications for Policymakers}

The Fogg Behaviour Model (FBM) is a theory of change model that could be considered for AAIs and student engagement to improve mental health outcomes [88]. In summary, FBM requires three elements for the intended behaviour of student engagement with AAIs to occur: motivation, ability and triggers [88]. Triggers promote the intended behaviours and may be achieved by advertisement/promotion of the sessions [88]. Motivation for attendance is proposed as the animals' presence addressing three core motivators: (1) hope of an experience that is likely to be (2) pleasurable and (3) socially acceptable for the majority [88]. Finally, to optimise the students' ability to participate in this intended behaviour, the model's six elements of simplicity should be addressed [88]:

1. time (sessions to be short)

2. money (sessions to be cost-neutral for students)

3. physical effort (sessions to be offered in an accessible location)

4. brain cycles (process by which to attend the sessions should be easy)

5. social acceptance (as offered by activities with animals)

6. routine (regular sessions to be offered)

For policymakers considering implementing AAIs in a higher educational setting, a logic model should be developed alongside the intervention to assist in clarifying the active ingredients and causal assumptions [89]. Key stakeholders, such as students from varying backgrounds, staff from student support services and animal/handler teams, should be involved during the design stage. A formative evaluation, including both process and implementation assessments, with a mixed-methods pilot study would be a 
useful first step [89-91]. The feasibility, acceptability and fidelity of the AAI in the target population can therefore be assessed with adaptation, if required. Thereafter, a summative evaluation, using a larger mixed-methods RCT, evaluating effectiveness, with a nested process evaluation, would be recommended [90].

\subsection{Future Research Recommendations}

Further research recommendations are detailed in Box 1. Particularly, the overall reporting quality by authors should be improved with facilitation from journals. For example, authors should provide enough information to allow replication of the interventions or expansion of the existing research [65]. These steps will help identify the effective or ineffective interventions and facilitate further evaluation of the active ingredients. Furthermore, potentially conflicting evidence, albeit not statistically significant, is present for mood which needs further evaluation to ensure that AAIs do not have unintended negative consequences [92]. Additionally, including animal welfare and economic evaluations are important to help secure support and funding from commissioners.

Box 1. The recommendations for future research for AAIs.

- Use of standardised and internationally recognised definitions when describing AAIs

- Use of sample sizes that provide adequate power

- Clarity regarding the randomisation procedure (including description of allocation, and whether concealed allocation occurred) and provision of an adequate description of the participants' characteristics separated by group

- Clear reporting of the participants' flow through the trial with reasons for any missing data for each respective group and at each time-point

- Use of explicit comparators to establish the relative effects of the co-interventions (e.g., appropriate attention controls)

- Adequate descriptions of the interventions implemented to facilitate replication

- Clear reporting of the outcome measurement procedure (particularly when multiple timepoints or stressors are present), including any adaptations made to the scales used

- Provision of access to publicly available pre-specified statistical analysis plans by authors, including justification for choice of target differences

- Clear reporting of adverse events for both humans and animals

\section{Conclusions}

Animal-assisted interventions (AAIs) were considered as potential interventions to help improve mental health and well-being of students in higher education who are willing to and can engage with animals. The pooled evidence suggests that AAIs could provide short-term beneficial results for anxiety, and possibly stress, in this population, known to be at risk of mental health issues. However, caution is required as these results were from studies at high risk of bias for the outcomes of interest for this systematic review with mostly medium strength evidence, and in various cultural settings. Subsequent implementation of AAIs in this setting requires both formative and summative evaluation to measure both the intended and unintended consequences. Furthermore, consideration of alternatives for students unable to participate due to fear of animals or medical contraindications is recommended to prevent widening of health inequalities.

Author Contributions: Conceptualization: C.P.-C., E.M., L.T.; methodology: C.P.-C., E.M., L.T.; validation: C.P.-C.; formal analysis: C.P.-C.; investigation: C.P.-C., M.L.; writing-original draft preparation: C.P.-C.; writing-review and editing: E.M., L.T., M.L.; supervision: E.M., L.T.; project administration: C.P.-C.; funding acquisition: not applicable. All authors have read and agreed to the published version of the manuscript.

Funding: This research received no external funding.

Institutional Review Board Statement: Not applicable with this study being a systematic review.

Informed Consent Statement: Not applicable. 
Data Availability Statement: Not applicable.

Acknowledgments: Catherine Richmond, Bogdan Metes, Cristina Fernandez-Garcia, Fiona Beyer, Fiona Pearson, Chris Marshall, Andy Bryant and all the authors who replied to our enquiries.

Conflicts of Interest: The authors declare no conflict of interest.

\section{Abbreviations}

\begin{tabular}{|c|c|}
\hline AAA & Animal-Assisted Activity \\
\hline AAC & Animal-Assisted Coaching \\
\hline AAE & Animal-Assisted Education \\
\hline AAI & Animal-Assisted Intervention \\
\hline AAT & Animal-Assisted Therapy \\
\hline ADHD & Attention Deficit Hyperactivity Disorder \\
\hline ANOVA & analysis of variance \\
\hline ANCOVA & analysis of covariance \\
\hline BDI-II & Beck Depression Inventory II \\
\hline DO & dog only \\
\hline EALS & equine-assisted learning supervision \\
\hline EPPI & Evidence for Policy and Practice Information \\
\hline ESRC & Economic and Social Research Council \\
\hline FBM & Fogg Behavioural Model \\
\hline F/up & follow-up \\
\hline HADS & Hospital Anxiety and Depression Scale \\
\hline HEI & higher education institute \\
\hline $\mathrm{HO}$ & handler only \\
\hline IAHAIO & $\begin{array}{l}\text { International Association of Human-Animal } \\
\text { Interaction Organizations }\end{array}$ \\
\hline IQR & interquartile range \\
\hline IRB & Institutional Review Boards \\
\hline MANCOVA & multivariate analysis of covariance \\
\hline MANOVA & multivariate analysis of variance \\
\hline $\mathrm{MeSH}$ & Medical Subject Headings \\
\hline MOS Social Support Scale & Medical Outcomes Study Social Support Scale \\
\hline NR & not reported \\
\hline NS & not significant \\
\hline PANAS & Positive and Negative Affect Schedule \\
\hline PASAT & Paced Auditory Serial Addition Task \\
\hline PICOS & Population, Intervention, Comparator, Outcome, Study design \\
\hline PSS & Perceived Stress Scale \\
\hline RCT & randomised controlled trial \\
\hline SART & Sustained Attention to Response Task \\
\hline SD & standard deviation \\
\hline SES & socioeconomic status \\
\hline SSS & student support services \\
\hline STAI & State-Trait Anxiety Inventory \\
\hline SWLS & Satisfaction with Life Score \\
\hline TIDieR & template for intervention description and replication \\
\hline UMACL & $\begin{array}{l}\text { University of Wales Institute of Science \& Technology Mood } \\
\text { Adjective Checklist }\end{array}$ \\
\hline UWIST & University of Wales Institute of Science \& Technology \\
\hline WAIQ Scale-IV & Wechsler Adult Intelligence Scale-IV \\
\hline WEMWBS & Warwick-Edinburgh Mental Well-being Scale \\
\hline Yrs & years \\
\hline
\end{tabular}

Appendix A

Search Strategies 
The search strategy was independently peer-reviewed by both an information specialist and an experienced librarian at Newcastle University.

MEDLINE through OVID (from 1946 to 28 April 2020):

(1) [Student $\$$ or pupil $\$$ or undergrad $\$$ or postgrad $\$$ or graduat $\$$ or freshm? $\mathrm{n}^{*}$ or sophomor $\$$ or junior $\$$ or senior $\$$ or learner $\$$ or scholar $\$$ or apprentic $\$$ or classmate\$].ti.kw.ab

(2) [junior\$ or senior\$] adj1 year\$].ti,kw,ab.

(3) Exp students /

(4) [colleg\$ or universit\$ or school\$ or conservator\$ or classroom $\$$ or apprenticeship $\$$ or facult\$].ti,kw,ab.

(5) [ [educat\$ or graduat\$ or undergrad\$ or academ $\$$ or junior $\$$ or senior $\$$ or postsecondary $\$$ or 'post secondary $\$$ '] adj1 [school\$ or colleg $\$$ or universit $\$$ or institut $\$$ or setting $\$$ or facult $\$$ or establish\$ or program $\$]] . t i, \mathrm{kw}, \mathrm{ab}$.

(6) [[seminar\$ or lectur\$] adj1 [room $\$$ or theatre $\$]$.ti, $\mathrm{kw}, \mathrm{ab}$

(7) Exp schools /

(8) Exp "internship and residency" /

(9) Exp faculty/

(10) Exp nursing faculty practice/

(11) Exp education, nonprofessional/

(12) Exp education, predental/

(13) Exp education, premedical/

(14) Exp education, professional/

(15) Exp inservice training/

(16) Exp international educational exchange/

(17) Exp "academies and institutes" /

(18) 1 or 2 or 3 or 4 or 5 or 6 or 7 or 8 or 9 or 10 or 11 or 12 or 13 or 14 or 15 or 16 or 17

(19) “human\$ animal\$ interact\$'.ti,ab,kw.

(20) Exp bonding, human-pet/

(21) 'human\$ animal\$ bond\$'.ti,ab,kw.

(22) Exp animal assisted therapy/

(23) [ [ animal $\$$ or pet $\$$ or $\operatorname{dog} \$$ or canine $\$$ or hound $\$$ or pooch $\$$ or pup $\$$ or cat $\$$ or feline $\$$ or kitt\$ or equine $\$$ or horse $\$$ or hippo $\$$ or pony $\$$ or foal $\$$ or riding $\$$ or 'guinea $\$$ pig\$' or rabbit\$ or bunn\$ or ferret\$ or hamster\$ or rodent\$ or mammal\$ or bird\$ or cow\$ or pig\$ or sheep\$ or lamb\$ or dolphin\$ or aquatic\$ or fish\$ or marine\$ or reptile\$] adj5 [therap\$ or intervent $\$$ or activit $\$$ or psychotherap $\$$ or interact $\$$ or visit $\$$ or program $\$]] . t i, k w, a b$.

(24) Exp equine-assisted therapy/

(25) 19 or 20 or 21 or 22 or 23 or 24

(26) Exp resilience, psychological/

(27) [Anxiet\$ or anxious $\$$ or worr $\$$ or concern $\$$ or apprehens $\$$ or nervous $\$$ or fear $\$$ or distress $\$$ or panic $\$$ or neuros $\$$ or apath $\$$ or $\operatorname{mood} \$$ or dread $\$$ or terror $\$$ or phobia $\$$ or irritable\$].ti,ab,kw.

(28) Exp psychological distress/

(29) Exp stress, psychological/

(30) Exp stress disorder, traumatic/

(31) Exp stress, physiological/

(32) [Stress $\$$ or burnout $\$$ or burn-out $\$$ or 'burn out'].ti,ab,kw.

(33) [Depress $\$$ or sad $\$$ or sorr $\$$ or unhapp $\$$ or grie $\$$ or lone $\$$ or happ $\$$ or dysthymia $\$$ ].ti,kw,ab.

(34) [Internali? adj1 [disorder\$ or symptom $\$$ or behavio\$]].ti,ab,kw.

(35) [Self $\$$ adj $/ 1$ [esteem $\$$ or accept $\$$ or confiden $\$$ or concept $\$]$ ].ti,ab,kw.

(36) [[Emotion\$ or mental\$] adj/1 [health\$ or illness\$ or wellbeing or well-being or 'well being]' or cop\$ or stress\$ or burnout or burn-out or 'burn out' or resilien\$]].ti,ab,kw

(37) Exp emotions/

(38) Exp depression/

(39) Exp mental health/ 
(40) Exp self concept/

(41) Exp mood disorders

(42) Exp anxiety disorders

(43) 26 or 27 or 28 or 29 or 30 or 31 or 32 or 33 or 34 or 35 or 36 or 37 or 38 or 39 or 40 or 41 or 42

(44) 18 and 25 and 43

PsycINFO through OVID (from 1806 to April Week 3 2020):

(1) [ [animal $\$$ or pet $\$$ or $\operatorname{dog} \$$ or canine $\$$ or hound $\$$ or pooch $\$$ or pup $\$$ or cat $\$$ or feline $\$$ or kitt\$ or equine\$ or horse $\$$ or hippo $\$$ or pony $\$$ or foal $\$$ or riding $\$$ or 'guinea $\$$ pig $\$$ ' or rabbit\$ or bunn\$ or ferret\$ or hamster\$ or rodent $\$$ or mammal $\$$ or bird\$ or cow $\$$ or pig $\$$ or sheep $\$$ or lamb\$ or dolphin $\$$ or aquatic $\$$ or fish $\$$ or marine $\$$ or reptile\$] adj5 [therap\$ or intervent $\$$ or activit $\$$ or psychotherap $\$$ or interact $\$$ or visit $\$$ or program $\$]] . t w$.

(2) “human\$ animal\$ interact\$".tw.

(3) “human\$ animal\$ bond\$".tw.

(4) Exp interspecies interaction/

(5) Exp animal assisted therapy/

(6) 1 or 2 or 3 or 4 or 5

(7) [college $\$$ or universit $\$$ or school $\$$ or conservator $\$$ or classroom $\$$ or apprenticeship $\$$ or faculty $\$] . t w$.

(8) [leducat $\$$ or graduat $\$$ or undergraduat $\$$ or academ $\$$ or junior $\$$ or senior $\$$ or postsecondary $\$$ or "postsecondary $\$$ "] adj1 [school\$ or colleg $\$$ or universit $\$$ or institut $\$$ or setting $\$$ or facult $\$$ or establish $\$$ or program $\$]] . t w$.

(9) [[seminar $\$$ or lectur $\$]$ adj1 [room $\$$ or theatre $\$]] . t w$.

(10) [high\$ adj1 educat\$].tw.

(11) Exp colleges/

(12) Exp schools/

(13) Exp classrooms/

(14) Exp apprenticeship/

(15) Exp higher education/

(16) Exp academic settings/

(17) Exp educational programs/

(18) Exp college environment/

(19) Exp educational degrees/

(20) Exp nursing education/

(21) Exp educational placement/

(22) Exp adult education/

(23) Exp academic environment/

(24) Exp campuses/

(25) [student $\$$ or pupil\$ or undergrad\$ or postgrad\$ or graduat $\$$ or freshm? $\mathrm{n}^{*}$ or sophomor $\$$ or junior $\$$ or senior $\$$ or learner $\$$ or scholar $\$$ or apprentic $\$$ or classmate $\$$ ].tw.

(26) [[junior\$ or senior\$] adj1 year\$].tw.

(27) Exp student/

(28) Exp classmates/

(29) 7 or 8 or 9 or 10 or 11 or 12 or 13 or 14 or 15 or 16 or 17 or 18 or 19 or 20 or 21 or 22 or 23 or 24 or 25 or 26 or 27 or 28

(30) [anxiet\$ or anxious $\$$ or worr $\$$ or concern $\$$ or apprehens $\$$ or nervous $\$$ or fear $\$$ or distress $\$$ or panic $\$$ or neuros $\$$ or apath $\$$ or $\operatorname{mood} \$$ or dread $\$$ or terror $\$$ or phobia $\$$ or irritable\$].tw

(31) [depress $\$$ or sad $\$$ or sorr $\$$ or unhapp $\$$ or grie $\$$ or lone $\$$ or happ $\$$ or dysthymia $\$$ ].tw.

(32) [stress $\$$ or burnout or burn-out or "burn out"].tw.

(33) [ [emotion\$ or mental\$] adj1 [health\$ or illness $\$$ or wellbeing or well-being or "wellbeing" or cop\$ or stress\$ or burnout or burn-out or "burn-out" or resilien\$]].tw.

(34) [internali? adj1 [disorder\$ or symptom\$ or behavio\$].tw. 
(35) [self adj1 [esteem $\$$ or accept $\$$ or confiden $\$$ or concept $\$$ ]].tw.

(36) Exp emotions/

(37) Exp anxiety disorders/

(38) Exp neurosis/

(39) Exp irritability/

(40) Exp affective disorders/

(41) Exp well being/

(42) Exp anhedonia/

(43) Exp mental health/

(44) Exp emotional adjustment/

(45) Exp "resilience [psychological]" /

(46) Exp coping behaviour/

(47) Exp internalization/

(48) Exp self-esteem/

(49) Exp self-perception/

(50) Exp self-concept/

(51) Exp stress

(52) 30 or 31 or 32 or 33 or 34 or 35 or 36 or 37 or 38 or 39 or 40 or 41 or 42 or 43 or 44 or 45 or 46 or 47 or 48 or 49 or 50 0r 51

(53) 6 and 29 and 52

Embase through OVID (from 1974 to 27 April 2020):

(1) “human\$ animal\$ interact\$".ti,ab,kw.

(2) “human\$ animal\$ bond\$". ti,ab,kw.

(3) [ [ animal\$ or pet $\$$ or $\operatorname{dog} \$$ or canine $\$$ or hound $\$$ or pooch $\$$ or pup $\$$ or cat $\$$ or feline $\$$ or kitt\$ or equine\$ or horse $\$$ or hippo $\$$ or pony $\$$ or foal $\$$ or riding $\$$ or 'guinea $\$$ pig $\$$ ' or rabbit\$ or bunn $\$$ or ferret\$ or hamster\$ or rodent $\$$ or mammal\$ or bird\$ or cow $\$$ or pig $\$$ or sheep $\$$ or lamb\$ or dolphin $\$$ or aquatic $\$$ or fish $\$$ or marine $\$$ or reptile\$] adj5 [therap $\$$ or intervent $\$$ or activit $\$$ or psychotherap $\$$ or interact $\$$ or visit $\$$ or program $\$]] . t i, a b, k w$.

(4) Exp animal assisted therapy/

(5) Exp human-animal bond/

(6) 1 or 2 or 3 or 4 or 5

(7) [colleg $\$$ or universit $\$$ or school $\$$ or conservator $\$$ or classroom $\$$ or apprenticeship $\$$ or facult\$].ti,ab,kw.

(8) [[seminar\$ or lectur\$] adj1 [room\$ or theatre\$]].ti,ab,kw.

(9) [high\$ adj1 educat\$].ti.ab.kw.

(10) [ [educat $\$$ or graduat $\$$ or undergraduat $\$$ or academ $\$$ or junior $\$$ or senior $\$$ or postsecondary $\$$ or "post secondary $\$$ "] adj 1 [school $\$$ or colleg $\$$ or universit $\$$ or institut $\$$ or setting $\$$ or facult $\$$ or establish $\$$ or program $\$]] . t i, a b, \mathrm{kw}$.

(11) Exp university/

(12) Exp college/

(13) Exp school/

(14) Exp school health service/

(15) Exp apprenticeship/

(16) Exp adult education/

(17) Exp doctoral education/

(18) Exp education program/

(19) Exp in service training/

(20) Exp medical education/

(21) Exp masters education/

(22) Exp paramedical education

(23) Exp postdoctoral education/

(24) Exp postgraduate education/

(25) Exp teacher training/ 
(26) 7 or 8 or 9 or 10 or 11 or 12 or 13 or 14 or 15 or 16 or 17 or 18 or 19 or 20 or 21 or 22 or 23 or 24 or 25

(27) [student $\$$ or pupil\$ or undergrad\$ or postgrad\$ or graduat $\$$ or freshm? $\mathrm{n}^{*}$ or sophomor $\$$ or junior $\$$ or senior $\$$ or learner $\$$ or scholar $\$$ or apprentic $\$$ or classmate $\$] . t i, a b, k w$.

(28) [[junior\$ or senior\$] adj1 year\$].ti,ab,kw.

(29) Exp student/

(30) Exp graduate/

(31) 27 or 28 or 29 or 30

(32) [anxiet $\$$ or anxious $\$$ or worr $\$$ or concern $\$$ or apprehens $\$$ or nervous $\$$ or fear $\$$ or distress $\$$ or panic $\$$ or neuros $\$$ or apath $\$$ or mood $\$$ or dread $\$$ or terror $\$$ or phobia $\$$ or irritable\$].ti,ab,kw.

(33) [depress $\$$ or sad $\$$ or sorr $\$$ or unhapp $\$$ or grie $\$$ or lone $\$$ or happ $\$$ or dysthymia $\$$ ].ti,ab, $\mathrm{kw}$.

(34) [stress\$ or burnout or burn-out or “burn out"].ti,ab,kw.

(35) [[emotion\$ or mental\$] adj1 [health\$ or illness\$ or wellbeing or well-being or "wellbeing" or cop\$ or stress $\$$ or burnout or burn-out or "burn-out" or resilien\$].ti,ab,kw.

(36) [internali? adj1 [disorder\$ or symptom\$ or behavio \$].ti, ab,kw.

(37) [self $\$$ adj1 [esteem $\$$ or accept $\$$ or confiden $\$$ or concept $\$$ ]].ti, ab, $\mathrm{kw}$

(38) Exp emotion/

(39) Exp anxiety disorder/

(40) Exp neurosis/

(41) Exp affect/

(42) Exp mood disorder/

(43) Exp stress/

(44) Exp temperament/

(45) Exp emotional disorder/

(46) Exp wellbeing/

(47) Exp coping behaviour/

(48) Exp psychological resilience/

(49) Exp mental health/

(50) Exp self concept/

(51) 32 or 33 or 34 or 35 or 36 or 37 or 38 or 39 or 40 or 41 or 42 or 43 or 44 or 45 or 46 or 47 or 48 or 49 or 50

(52) 26 or 31

(53) 6 and 51 and 52

The Cochrane Central Register of Controlled Trials (CENTRAL) (from inception to 23 April 2020):

(1) [Anxiet* or anxious* or worr* or concern* or apprehens* or nervous* or fear* or distress* $^{*}$ or panic ${ }^{*}$ or neuros* or apath* or mood* or dread* or terror* or phobia* or irritable*]:ti,ab,kw

(2) [Depress* or sad* or sorr* or unhapp* or grie* or lone* or happ* or dysthymia*]:ti.ab.kw

(3) [Stress* or burnout or burn-out or [burn NEXT out]]:ti,ab,kw

(4) [[Emotion* or mental $\left.{ }^{*}\right]$ NEAR/1 [health* or illness* or wellbeing or well-being or [well NEXT being] or cop* or stress* or burnout or burn-out or [burn NEXT out] or resilien*]]:ti,ab,kw

(5) [[Internali? NEAR/1 [disorder* or symptom* or behavio*]]]:ti,ab,kw

(6) [Self* NEAR/1 [esteem* or accept* or confiden* or concept $\left.\left.{ }^{*}\right]\right]: t i, a b, k w$

(7) MeSH descriptor: [Anxiety] explode all trees

(8) MeSH descriptor: [Anxiety Disorders] explode all trees

(9) MeSH descriptor: [Emotions] explode all trees

(10) MeSH descriptor: [Emotional Adjustment] explode all trees

(11) MeSH descriptor: [Expressed Emotion] explode all trees

(12) MeSH descriptor: [Mood Disorders] explode all trees

(13) MeSH descriptor: [Depression] explode all trees

(14) MeSH descriptor: [Trauma and Stressor Related Disorders] explode all trees 
(15) MeSH descriptor: [Stress, Psychological] explode all trees

(16) MeSH descriptor: [Affective Symptoms] explode all trees

(17) MeSH descriptor: [Mental Health] explode all trees

(18) MeSH descriptor: [Resilience, Psychological] explode all trees

(19) MeSH descriptor: [Self Concept] explode all trees

(20) OR \#1-\#19

(21) [student* or pupil* or undergrad* or postgrad* or graduat* or freshm?n* or sophomor ${ }^{*}$ or junior* or senior* or learner* or scholar* or apprentic* or classmate* $]: t i, a b, k w$

(22) [[junior* or senior*] NEAR/1 year*].ti,ab,kw

(23) MeSH descriptor: [Students] explode all trees

(24) OR \#21-\#23

(25) [colleg* ${ }^{*}$ universit*or school* ${ }^{*}$ or conservator* ${ }^{*}$ or classroom* or apprenticeship* or facult*]:ti,ab,kw

(26) [[educat* or graduat* or undergraduat $^{*}$ or academ* or junior* or senior* or postsecondary* or [post NEXT secondary*] NEAR/1 [school* or colleg* or universit* or institut* or setting* or facult* or establish* or program*]]:ti,ab,kw

(27) [[seminar* or lectur*] NEAR/1 [room* or theatre*]]:ti,ab,kw

(28) [high* NEAR/1 educat*]:ti.ab.kw

(29) MeSH descriptor: [College Fraternities and Sororities] explode all trees

(30) MeSH descriptor: [Universities] explode all trees

(31) MeSH descriptor: [Schools] explode all trees

(32) MeSH descriptor: [Clinical Clerkship] explode all trees

(33) MeSH descriptor: [Educational, nonprofessional] explode all trees

(34) MeSH descriptor: [Educational, professional] explode all trees

(35) MeSH descriptor: [Educational, predental] explode all trees

(36) MeSH descriptor: [Educational, premedical] explode all trees

(37) MeSH descriptor: [International Educational Exchange] explode all trees

(38) MeSH descriptor: [Inservice Training] explode all trees

(39) MeSH descriptor: [Academies and Institutes] explode all trees

(40) OR \#25-39

(41) [human* NEXT animal* NEXT interact*].ti,ab,kw

(42) [human* NEXT animal* NEXT bond*].ti,ab,kw

(43) MeSH descriptor: [Bonding, Human-Pet] explode all trees

(44) MeSH descriptor: [Animal Assisted Therapy] explode all trees

(45) MeSH descriptor: [Equine-assisted therapy] explode all trees

(46) [[ [animal* ${ }^{*}$ or pet* or dog* or canine* or hound* or pooch* or pup* or cat* or feline* or kitt* or equine* or horse* or hippo* or pony* or foal* or riding* or [guinea* NEAR pig*] or rabbit* or bunn* or ferret* or hamster* or rodent* or mammal* or bird* or cow $^{*}$ or pig* or sheep* or lamb* or dolphin* or aquatic* or fish* or marine* or reptile*] NEAR/5 [therap* or intervent* or activit* or psychotherap* or interact* or visit* or program*]]]:ti,ab,kw

(47) OR \#41-\#46

(48) \#24 OR \#40

(49) \#47 AND \#48 AND \#20

Grey literature through Advanced Google Search on 1 May 2020:

Not signed in and as Google sorts by relevance first FOUR pages reviewed:

1st search: ["animal assisted therapy" OR "pet therapy"] AND [university OR college] AND [anxiety OR stress]

2nd search: ["human animal interaction" OR "animal assisted intervention"] AND [university OR college] AND [anxiety OR stress]

3rd search: ["animal assisted therapy" OR "pet therapy"] AND [undergraduate OR postgraduate] AND [anxiety OR stress]

4th search: ["human animal interaction" OR "animal assisted intervention"] AND [undergraduate OR postgraduate] AND [anxiety OR stress] 
PROSPERO International Prospective Register of Systematic Reviews on 4 May 2020:

Search terms used:

Human animal interaction

Human animal bond

Animal therapy

Animal-assisted therapy

Animal-assisted activity

Animal-assisted intervention

Then all combinations of [pet, dog, canine, hound, pooch, puppy, cat, feline, kitty, equine, horse, hippo, pony, foal, riding, guinea pig, rabbit, bunny, ferret, hamster, rodent, mammal, bird, cow, pig, sheep, lamb, dolphin, fish, aquatic, marine, or reptile] with [therapy, intervention, activity, psychotherapy, interaction, visit, or program]

\section{Appendix B}

Additional decision rules for RoB2 assessment and vote counting

RoB2 Assessment:

The decision rules were developed and applied to the RoB2 assessment to standardise the approach when information was lacking in the RoB2 guidance on how to approach. The specific domains and questions are taken directly from the RoB2 tool $[67,68]$.

"Domain 1: Risk of bias arising from the randomisation process

1.3: Did baseline differences between intervention groups suggest a problem with the randomisation process?"

To allocate "No" /"Probably No" or "Yes" /"Probably Yes": the baseline differences of the participants had to be split by each group to be able to compare. Additionally, the authors had to ensure it was clearly stated (either in the narrative or in Tables/Figures) that the characteristics were for the randomised participants. Providing only a statement regarding the characteristics for the whole group or a statement regarding statistical differences between the groups were not enough.

Otherwise, the grading of "No Information" was allocated.

"Domain 2: Risk of bias due to deviations from the intended interventions (effect of assignment to intervention)

2.6: Was an appropriate analysis used to estimate the effect of assignment to intervention?"

"Probably Yes" was allocated if all missing information was specified with reasons and the trialists did not state if deviations had occurred. The rationale was that the trialist may not state that deviations had not occurred due to word-count issues. Deviations are reportable to the relevant Institutional Review Boards (IRB) in accordance with ethical approval and trialists are expected to state deviations (if they occurred) according to good research practice.

"2.7: Was there potential for a substantial impact (on the result) of the failure to analyse participants in the group to which they were analysed?"

"Probably No" was allocated if excluded or missing data were less than 5\% with appropriate reasons why.

"Domain 3: Risk of bias due to missing outcome data

3.1: Were data for this outcome available for all, or nearly all, participants randomised?"

For the allocation of "Yes" or "Probably Yes": the authors had to clearly state the amount of missing data either in the narrative or in a Table/Figure and had to be less than $5 \%$.

"No" was allocated if the missing data were more than $5 \%$.

"No Information" was allocated if the amount of missing data was not clearly stated in either the narrative or Tables/Figures.

"3.3. Could missingness in the outcome depend on its true value?"

"No" was allocated if reasons were provided for the missing data and the reasons were not related to the outcome. 
"Yes" was allocated if reasons were given and related to the outcome.

"No Information" was allocated if no reasons were provided.

If 3.4 required a response: "Is it likely that missingness in the outcome depended on its true value?"

"No information" was allocated if no reasons were provided for the missing data and the amount that were missing in each group was not clearly stated.

"Domain 4: Risk of bias in measurement of the outcome:

4.5: Is it likely that assessment of the outcome was influenced by knowledge of intervention received?"

Due to the nature of the intervention, even if the participants were blinded to the study's purpose: "Yes" or "Probably Yes" was allocated.

"Domain 5: Risk of bias in selection of the reported results:

5.1 Were the data that produced the results in accordance with a pre-specified analysis plan that was finalised before unblinded outcomes data were available for analysis?"

For "Yes" to be allocated, the authors were required to publish their pre-specified analysis protocol in the public domain.

For "No" to be allocated, the authors had to both confirm pre-specified analysis protocol was not published and analysis was, indeed, not in accordance with an unpublished pre-specified plan.

"No Information" was allocated if no published pre-specified plan.

" 5.2 : Is the numerical result being assessed likely to have been selected, on the basis of the results from multiple eligible outcome (e.g., scales, definitions, time-points) within the outcome domain?"

"No" was allocated if the outcomes were measured at similar times in the same order with the same measures and same mode of administration for the groups involved.

"Yes" was allocated if the above elements varied.

"No information" was allocated if not enough information was given to assess adequately.

"5.3: Is the numerical result being assessed likely to have been selected, on the basis of the results, from multiple eligible analyses of the data?"

For "Yes" to be allocated, evidence was required to suggest multiple analyses had occurred either through the available information or through correspondence with the authors.

"No" was allocated if a pre-specified analysis protocol was published or the authors confirmed that the analysis was in accordance with a pre-specified unpublished analysis plan which was then made available for reviewers to examine.

"No Information" was allocated if the above criteria were not met.

Vote counting:

Table A1 summarises the decision criteria for both without and with a stressor. Specifically, in situations where a stressor was present, the expected response without the intervention was considered. For example, after a stressor (e.g., an experimental cognitive test) or before a known stressor (e.g., exam), the expectation is that anxiety scores are likely to be worse than baseline. For the intervention to have a beneficial effect when a stressor was present, three situations could occur:

(1) anxiety was worse after the intervention (as expected due to the stressor) but not by as much as the control group

(2) no change seen after the intervention, but anxiety was worse in the control group

(3) anxiety was better after the intervention and better than the control group 
Table A1. Decision criteria to aid interpretation of vote counting.

\begin{tabular}{|c|c|}
\hline Interpretation & Requirements \\
\hline \multicolumn{2}{|c|}{ Without a stressor } \\
\hline Beneficial & $\begin{array}{l}\text { Post-intervention assessment shows improvement in scores } \\
\text { (direction relative to the measure used) compared to } \\
\text { pre-assessment and better than control }\end{array}$ \\
\hline \multirow{4}{*}{ No } & Post-intervention assessment: \\
\hline & (1) shows no change in scores compared to pre-assessment \\
\hline & \\
\hline & $\begin{array}{l}\text { (2) improvement in scores (direction relative to the measure } \\
\text { used) compared to pre-assessment but not } \\
\text { as much as control }\end{array}$ \\
\hline Detrimental & $\begin{array}{l}\text { Post-intervention assessment shows worsening in scores } \\
\text { (direction relative to the measure used) compared to } \\
\text { pre-assessment and worse than control }\end{array}$ \\
\hline \multicolumn{2}{|c|}{$\begin{array}{l}\text { With a stressor (either before the post-assessment or present during post-assessment, e.g., } \\
\text { occurring prior to an exam) }\end{array}$} \\
\hline \multirow{6}{*}{ Beneficial } & Post-intervention assessment shows: \\
\hline & $\begin{array}{l}\text { (1) worsening in scores (direction relative to the measure used) } \\
\text { compared to pre-assessment as would be expected due to } \\
\text { stressor but less than the control }\end{array}$ \\
\hline & \\
\hline & (2) no change with the control scores being worse \\
\hline & \\
\hline & (3) an improvement in scores which are better than the control \\
\hline Detrimental & $\begin{array}{l}\text { Post-intervention assessment shows worsening in scores } \\
\text { (direction relative to the measure used) compared to } \\
\text { pre-assessment as would be expected due to stressor and worse } \\
\text { than control }\end{array}$ \\
\hline
\end{tabular}

\section{Appendix C}

Table A2. Full text excluded studies with reasons $(n=122)$.

\begin{tabular}{ll}
\hline $\begin{array}{l}\text { References of Excluded Studies from Full } \\
\text { Manuscript Search }\end{array}$ & Reason Excluded \\
\hline Adamle et al. [93] & wrong study design \\
\hline Adams et al. [94] & wrong study design \\
\hline Adams et al. [95] & wrong study design \\
\hline Alonso [96] & criteria for inter-library loan not met \\
\hline Anderson [97] & wrong outcome measures \\
\hline Anonymous [98] & criteria for inter-library loan not met \\
\hline Anonymous [99] & wrong study design \\
\hline Ashton [100] & wrong study design \\
\hline Baghain et al. [101] & wrong study design \\
\hline Bajorek [102] & wrong outcomes \\
\hline Barker et al. [103] & wrong outcomes \\
\hline
\end{tabular}


Table A2. Cont.

\begin{tabular}{|c|c|}
\hline $\begin{array}{l}\text { References of Excluded Studies from Full } \\
\text { Manuscript Search }\end{array}$ & Reason Excluded \\
\hline Barker et al. [104] & wrong outcomes \\
\hline Barker et al. [105] & wrong study design \\
\hline Barlow et al. [106] & wrong intervention \\
\hline Basil et al. [107] & wrong study design \\
\hline Behnke et al. [108] & wrong study design \\
\hline Bell [2] & wrong study design \\
\hline Beutler et al. [109] & wrong study design \\
\hline Biery [110] & criteria for inter-library loan not met \\
\hline Binfet et al. [111] & wrong study design \\
\hline Binfet et al. [112] & wrong study design \\
\hline Binfet et al. [113] & no comparator \\
\hline Bjick [114] & wrong study design \\
\hline Blender [115] & wrong intervention \\
\hline Brelsford et al. [13] & wrong population \\
\hline Broeyer et al. [116] & criteria for inter-library loan not met \\
\hline Buttelmann et al. [117] & wrong study design \\
\hline Chakales et al. [118] & wrong study design \\
\hline Chramouleeswaran et al. [119] & wrong population \\
\hline Cieslak [120] & wrong outcomes \\
\hline ClinicalTrials.gov [121] & wrong intervention \\
\hline ClinicalTrials.gov [122] & wrong outcomes \\
\hline ClinicalTrials.gov [123] & wrong outcomes \\
\hline ClinicalTrials.gov [124] & not included as trial still ongoing \\
\hline Colarelli et al. [125] & wrong intervention \\
\hline Coleman et al. [126] & wrong outcomes \\
\hline Crago et al. [127] & wrong study design \\
\hline Crossman et al. [6] & wrong study design \\
\hline Crossman et al. [36] & wrong study design \\
\hline Crump et al. [21] & wrong study design \\
\hline Daltry et al. [34] & wrong study design \\
\hline Delgado et al. [128] & wrong study design \\
\hline Dell et al. [129] & wrong study design \\
\hline Dhooper et al. [130] & wrong study design \\
\hline Dluzynski [131] & wrong outcomes \\
\hline Duffey T [132] & wrong study design \\
\hline Flaherty [133] & wrong intervention \\
\hline Folse et al. [134] & wrong study design \\
\hline Frederick [135] & wrong population \\
\hline Frederick et al. [136] & wrong population \\
\hline Friedmann et al. [137] & wrong outcomes \\
\hline
\end{tabular}


Table A2. Cont.

\begin{tabular}{|c|c|}
\hline $\begin{array}{l}\text { References of Excluded Studies from Full } \\
\text { Manuscript Search }\end{array}$ & Reason Excluded \\
\hline Gonzalez-Ramirez et al. [138] & wrong outcomes \\
\hline Goodkind et al. [139] & wrong population \\
\hline Gress [140] & criteria for inter-library loan not met \\
\hline Haggerty et al [141] & wrong study design \\
\hline Hammer et al. [142] & wrong study design \\
\hline Hemingway et al. [143] & wrong study design \\
\hline Henry [144] & wrong intervention \\
\hline House et al. [145] & wrong study design \\
\hline Ishimura et al. [146] & wrong intervention \\
\hline Jarolmen et al. [147] & wrong outcomes \\
\hline Johnson [148] & wrong study design \\
\hline King [149] & wrong study design \\
\hline Kobayashi et al. [150] & wrong outcomes \\
\hline Kronholz et al. [151] & wrong study design \\
\hline Kuzara et al. [152] & wrong outcomes \\
\hline Lacoff et al. [153] & wrong study design \\
\hline Lauriente et al. [154] & wrong study design \\
\hline Lephart et al. [155] & wrong study design \\
\hline Linden [156] & criteria for inter-library loan not met \\
\hline Litwiller et al. [157] & wrong study design \\
\hline Machova et al. [158] & wrong study design \\
\hline Malakoff [159] & wrong population \\
\hline Manor [160] & criteria for inter-library loan not met \\
\hline Marino [161] & wrong study design \\
\hline Matsuura et al. [162] & wrong intervention \\
\hline McArthur et al. [163] & wrong study design \\
\hline McCrindle [164] & criteria for inter-library loan not met \\
\hline McDonald et al. [165] & wrong intervention \\
\hline Merritt [166] & criteria for inter-library loan not met \\
\hline Morrison [15] & wrong study design \\
\hline Morgan [167] & wrong study design \\
\hline Muckle et al. [168] & wrong study design \\
\hline Muellmann et al. [169] & wrong study design \\
\hline Nocentini et al. [170] & wrong study design \\
\hline Pendry et al. [171] & wrong outcomes \\
\hline Pendry et al. [172] & wrong outcomes \\
\hline Pendry et al. [173] & wrong outcomes \\
\hline Pendry et al. [174] & wrong outcomes \\
\hline Pendry et al. [175] & wrong intervention \\
\hline
\end{tabular}


Table A2. Cont.

\begin{tabular}{|c|c|}
\hline $\begin{array}{l}\text { References of Excluded Studies from Full } \\
\text { Manuscript Search }\end{array}$ & Reason Excluded \\
\hline Perry et al. [176] & wrong study design \\
\hline Picard [177] & wrong intervention \\
\hline Polking et al. [178] & wrong study design \\
\hline Quinn et al. [179] & wrong study design \\
\hline Ralston et al. [180] & wrong study design \\
\hline Renne et al. [181] & wrong study design \\
\hline Robino et al. [182] & wrong study design \\
\hline Robson [183] & wrong study design \\
\hline Rose [184] & wrong study design \\
\hline Sanford [185] & wrong study design \\
\hline Silas et al. [186] & wrong study design \\
\hline Sola-Perkins [187] & wrong population \\
\hline Stewart et al. [188] & wrong intervention \\
\hline Stewart et al. [189] & wrong study design \\
\hline Straatman et al. [190] & wrong intervention \\
\hline Swan [191] & criteria for inter-library loan not met \\
\hline Taylor et al. [192] & wrong study design \\
\hline Thelwell [193] & wrong intervention \\
\hline Thew [194] & wrong outcomes \\
\hline Tobin [195] & wrong population \\
\hline Tomaszewska et al. [196] & wrong study design \\
\hline Trammell [197] & wrong outcomes \\
\hline Turner et al. [198] & wrong study design \\
\hline Voelpel et al. [199] & wrong study design \\
\hline Walsh [200] & wrong study design \\
\hline Wheeler et al. [201] & wrong intervention \\
\hline Williams et al. [202] & wrong outcomes \\
\hline Wilson [203] & not available due to COVID-19 \\
\hline Wilson [204] & not available due to COVID-19 \\
\hline Wood et al [205] & no comparator \\
\hline Young [206] & wrong reporting of outcomes \\
\hline Zents et al. [207] & wrong population \\
\hline
\end{tabular}

\section{Appendix D. Summary of the Theoretical Frameworks and Results}

Theoretical frameworks:

For a study to be classed as clearly stating the theoretical framework that underpinned the included intervention, one of the following criteria was required:

- mechanism of action was stated and directly linked back to the intervention's development before implementation; or 
- $\quad$ proposal was offered for the intervention's mechanism of action on the outcomes before the intervention was implemented; or

- mechanism of action was stated with a pre-specified assessment to distinguish the different co-interventions' relative effects

Three of the included studies were assessed as articulating the theoretical framework according to the above $[35,37,80]$ :

- Binfet [35] used Biophilia and Cobb's Social Support Theory [24,26] stating that the study was "designed to both facilitate group interactions \& human-animal relationship, factors theorized to contribute to stress reduction" ([35] p. 399).

- Grajfoner et al. [37] suggested that a benefit of dog-assisted interventions is "encouraging students to perceive counseling services as more accessible" \& "therapy dogs represent a source of comfort, acceptance \& de-stress" ([37] p. 2) with the study aimed to work out the relative influence of the dogs.

- Meola [80] considered experiential learning to address the structure proposed by Larson's Social Cognitive Model of Counsellor Training (based on Banduras Social Cognitive Theory) as cited by Meola [80].

Seven of the included studies partially articulated the theoretical framework according to the above criteria [73-79]:

- $\quad$ Fiocco et al. [73] discussed the presence of therapy animal may act as a buffer of stress with no further expansion.

- Gebhart et al. [74] suggested distraction-focused techniques are "capable of creating some kind of break \& may help students feel better" ([74] p. 3) with evidence that distraction techniques have reduced anxiety in other settings.

- Hall [75] applied Kolcaba's Midrange Theory of Comfort [208] from patients to students. Suggested that students who reach transcendence (highest level of comfort) "would be empowered to rise above the challenges of nursing education" ([75] p. 203). Stating how \& why dogs could help with achieving transcendence was not explicitly included.

- Hunt et al. [76] described the intervention of interest initially as a placebo control and in the discussion theorized the role of social support, community \& sense of belonging.

- Shearer et al. [77] described the intervention of interest as an active control and in the discussion considered unconditional positive regard \& social environment.

- Ward-Griffin et al. [78] suggested that therapy animals may act as a source of social support with no further expansion.

- Williams et al. [79] reported that therapy animals are trained to provide comfort, affection \& can be calming with no further expansion.

One study [72] was assessed as not articulating the theoretical framework according to the above criteria:

- Banks et al. [72] discussed the benefits of canine interaction, for example the cognitive changes with reducing mind wandering \& increasing sustained attention but did not explore how \& why mental health outcomes would be improved.

Results:

Box A1 aids with interpretation of mean change scores and Table A3 provides summary of the results. 
Box A1. Interpretation of the mean change scores (post-scores minus pre-scores) for each outcome measures; one example of the change score is presented with the inverse being true for the alternative option.

Anxiety as measured by:
STAI (regardless of subscale): negative change = anxiety decreases
HADS-anxiety subscale: negative change = anxiety decreases
Stress as measured by:
PSS: negative change = stress decreases
Depression as measured by:
BDI II: negative change = depression decreases
HADS-depression subscale: negative change = depression decreases
Mood/affect as measured by:
PANAS positive: negative change = positive mood decreases
PANAS negative: negative change = negative mood decreases
WMACL (depends on subscale): inference in paper was positive change = mood increases
Well-being as measured by:
WEMWBS: positive change = mental well-being increases
Subjective Happiness Scale: positive change $=$ happiness increases
Total social support: positive change = total levels of support increases
SWLS (based on brackets): 5-9 = extremely dissatisfied; $15-19=$ slightly dissatisfied; $20=$ neutral;
21-25 = slightly satisfied; $26-30=$ satisfied and as both groups in the same bracket that a negative
score = satisfaction with life decreases




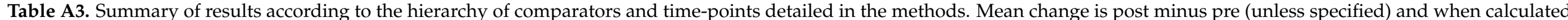
by review SD cannot be provided. Vote counting is according to description in methods. NS = non-significant; NR = not reported. F/up = follow up.

\begin{tabular}{|c|c|c|c|c|c|c|c|}
\hline Author \& Year & Sample Size & Outcome & $\begin{array}{l}\text { Findings with Effect Measures \& } \\
\text { Statistical Test Used by Authors }\end{array}$ & $p$ Value & $\begin{array}{l}\text { Evidence } \\
\text { Strength }\end{array}$ & Vote Count & Conclusions \\
\hline $\begin{array}{l}\text { Banks [72] } \\
2018\end{array}$ & $\begin{array}{l}\text { Randomised: } n=56 \\
(n=29 \text { dog; } \\
n=27 \text { no-treatment control) } \\
\text { Analysed: unclear }\end{array}$ & $\begin{array}{l}\text { PANAS positive } \\
\text { PANAS negative }\end{array}$ & $\begin{array}{l}\text { Mean change after stressor; } \\
\text { calculation by review. } \\
\text { Positive mood (PANAS positive): } \\
\text { Treatment: -4.51 } \\
\text { No-treatment control: }-3.48 \\
\text { Negative mood } \\
\text { (PANAS negative): } \\
\text { Treatment: 0.21 } \\
\text { Not-treatment control:- }-0.82 \\
\text { Mixed modal ANOVAs for change } \\
\text { over time \& if moderated } \\
\text { by condition }\end{array}$ & $\begin{array}{l}\text { Mood: } \\
\text { PANAS positive: } p>0.05 \text { (NS) } \\
\text { for condition or } \\
\text { time } \times \text { condition } \\
\text { PANAS negative: } p>0.05 \text { (NS) } \\
\text { for time, condition, } \\
\text { time x condition }\end{array}$ & $\begin{array}{l}\text { Overall weight: } \\
\text { low }\end{array}$ & $\begin{array}{l}\text { Mood (with stressor): } \\
\text { PANAS positive \& negative: } \\
\text { Detrimental }\end{array}$ & $\begin{array}{l}\text { Measurement occurred after a } \\
\text { 10-min group free interaction single } \\
\text { AAA session with a stressor applied } \\
\text { before measurement } \& \text { sessions } \\
\text { occurred during exam week). } \\
\text { NS reduction in positive mood for } \\
\text { both groups when condition } \\
\text { or condition } \times \text { time reviewed } \\
\text { (treatment more than control). NS } \\
\text { slight worsening of negative mood } \\
\text { for treatment group. } \\
\text { Where NS, no power calculation so } \\
\text { unable to say if no true effect or } \\
\text { if underpowered. }\end{array}$ \\
\hline Binfet [35] 2017 & $\begin{array}{l}\text { Randomised: } n=163 \\
\text { Analysed: } n=155 \\
(n=81 \text { therapy dog; } \\
n=74 \text { no-treatment control e.g., } \\
\text { studying) }\end{array}$ & $\begin{array}{l}\text { PSS } \\
\text { Sense of } \\
\text { Belonging in School }\end{array}$ & $\begin{array}{l}\text { Mean change (SD) } \\
\text { Stress (PSS): } \\
\text { Treatment: -0.17 (0.03) } \\
\text { No-treatment control: 0.02 (0.04) } \\
\text { Well-being proxy (School } \\
\text { belonging:: } \\
\text { Treatment: } 0.1 \text { ( (0.03) } \\
\text { No-treatment control: - } 0.05 \text { (0.03) } \\
\text { Used MANCOVA controlling for } \\
\text { gender (inferred same approach } \\
\text { with ANCOVA) }\end{array}$ & $\begin{array}{l}\text { ANCOVA over time: treatment } \\
\text { group vs. control } \\
\text { Immediate: } \\
\text { Stress: } p<0.001 \\
\text { Well-being: } p=0.002(<0.05) \\
\text { 2-week } \mathrm{f} / \text { up: NS }\end{array}$ & Overall weight: medium & $\begin{array}{l}\text { Stress: } \\
\text { Beneficial } \\
\text { Well-being: } \\
\text { Beneficial }\end{array}$ & $\begin{array}{l}\text { Compared to control, statistical } \\
\text { significance with improved scorres } \\
\text { were shown for both perceived stress } \\
\text { (reduced) \& school belonging } \\
\text { (increased) for the treatment group (a } \\
\text { 20-min group free interaction single } \\
\text { AAT session). } \\
\text { NS difference between the two } \\
\text { groups at 2-week follow-up but no } \\
\text { power calculation so unable to say if } \\
\text { truly 'no effect' or if underpowered. }\end{array}$ \\
\hline $\begin{array}{l}\text { Fiocco [73] } \\
2017\end{array}$ & $\begin{array}{l}\text { Randomised: } n=61 \\
(n=31 \text { dog; } \\
n=30 \text { no-treatment control) } \\
\text { Analysed: unclear }\end{array}$ & $\begin{array}{l}\text { PANAS positive } \\
\text { PANAS negative }\end{array}$ & $\begin{array}{l}\text { Mean change inferred post minus } \\
\text { pre after stressor (SD) } \\
\text { Positive mood (PANAS positive): } \\
\text { Treatment: - } 0.35 \text { (6.66) } \\
\text { No-treatment control:-4.37 (7.15) } \\
\text { Negative mood (PANAS } \\
\text { negative): } \\
\text { Treatment: } 2.29 \text { (5.62) } \\
\text { No-treatment control: } 0.6 \text { (6.1) } \\
\text { ANCOVA controlling for } \\
\text { baseline effect }\end{array}$ & $\begin{array}{l}\text { Mood: } \\
\text { PANAS positive } \\
p=0.08 \text { (NS) } \\
\text { PANAS negative } \\
p=0.61 \text { (NS) }\end{array}$ & Overall weight: medium & $\begin{array}{l}\text { Mood (with stressor): } \\
\text { PANAS positive: } \\
\text { Beneficial } \\
\text { PANAS negative: } \\
\text { Detrimental }\end{array}$ & $\begin{array}{l}\text { For this individual free interaction } \\
\text { 10-min single AAA session and } \\
\text { subsequent stressor: } \\
\text { Positive mood reduces (NS) for both } \\
\text { but was worse for control. } \\
\text { Negative mood was worse (NS) for } \\
\text { both groups but more so for } \\
\text { treatment group. } \\
\text { Where NS, no power calculation so } \\
\text { unable to say if no true effect or } \\
\text { if underpowered. }\end{array}$ \\
\hline $\begin{array}{c}\text { Gebhart [74] } \\
2019\end{array}$ & $\begin{array}{l}\text { Randomised: } n=72 \\
\text { Analysed: } n=57 \\
\text { (n=12 therapy dog; } \\
n=15 \text { no-treatment control } \\
\text { (unstructured free hour); } n=14 \\
\text { body percusion; } n=16 \\
\text { mandala painting) }\end{array}$ & STAI-S & $\begin{array}{l}\text { Median change trends reported as } \\
\text { relevant results only presented } \\
\text { in graphs } \\
\text { Anxiety (STAI-S): } \\
\text { Normal day: } \\
\text { Treatment: reduction } \\
\text { No-treatment control: } \\
\text { small increase } \\
\text { Prior to exam (stressor): } \\
\text { Treatment: small reduction } \\
\text { No-treatment control: an increase } \\
\text { Wilcoxon signed-rank tests }\end{array}$ & $\begin{array}{l}\text { Anxiety: } \\
\text { Normal day } p<0.01 \text { for therapy } \\
\text { dog; NS for control } \\
\text { Exam day } p=\text { NS for both } \\
\text { therapy dog \& control }\end{array}$ & Overall weight: high & $\begin{array}{l}\text { Anxiety } \\
\text { (without stressor): } \\
\text { Beneficial }\end{array}$ & $\begin{array}{l}\text { On a normal day (after two } \\
\text { structured group AAT interventions } \\
\text { lasting } 45-60 \text { min of unknown time } \\
\text { between sessions) a statistically } \\
\text { significicant reduction in anciety was } \\
\text { found in therapy dog group. } \\
\text { On an exam day (after three } \\
\text { structured group AAT interventions } \\
\text { lasting } 45-60 \text { min of unknown time } \\
\text { between sessions) NS difference in } \\
\text { andiety was found in both therapy } \\
\text { dog \& control group. } \\
\text { Where NS, no power calculation so } \\
\text { unable to say if no true effect or } \\
\text { if underpowered. }\end{array}$ \\
\hline
\end{tabular}


Table A3. Cont.

\begin{tabular}{|c|c|c|c|c|c|c|c|}
\hline Author \& Year & Sample Size & Outcome & $\begin{array}{l}\text { Findings with Effect Measures \& } \\
\text { Statistical Test Used by Authors }\end{array}$ & $p$ Value & $\begin{array}{l}\text { Evidence } \\
\text { Strength }\end{array}$ & Vote Count & Conclusions \\
\hline$\underset{2017}{\text { Grajfoner [37] }}$ & $\begin{array}{l}\text { Randomised: Unclear; } \\
n=132 \text { recruited } \\
\text { Analysed: } n=132 \\
(n=45 \text { dog with handler; } n=46 \\
\text { handler only (HO) \& } n=41 \mathrm{dog} \\
\text { only (DO)) }\end{array}$ & $\begin{array}{l}\text { STAI } \\
\text { WEMWBS } \\
\text { UMACL }\end{array}$ & 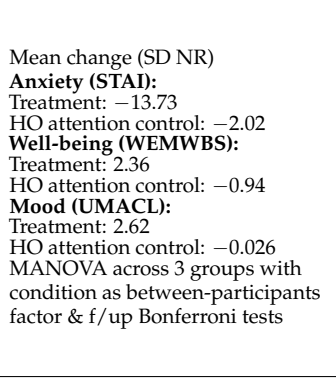 & $\begin{array}{l}\text { Anxiety: } p<0.001 \\
\text { Well-being: } p<0.001 \\
\text { Mod: NS (exact } p \text { value NR) }\end{array}$ & Overall weight: medium & $\begin{array}{l}\text { Anxiety: } \\
\text { Beneficial } \\
\text { Well-being: } \\
\text { Beneficial } \\
\text { Mood: } \\
\text { Beneficial }\end{array}$ & $\begin{array}{l}\text { A free interaction 20-min single } \\
\text { group AAA session demonstrated: } \\
\text { (1) anxiety scores reduced for both } \\
\text { dog with handler \& control groups } \\
\text { which was statistically significiant in } \\
\text { favour of the dog with handler group } \\
\text { (2) statistically significant } \\
\text { improvement in well-being in favour } \\
\text { of the dog with handler group } \\
\text { (3) NS significant improvement in } \\
\text { mood (increased in dog with handler } \\
\text { group with reduction in control) } \\
\text { Where NS, no power calculation so } \\
\text { unable to say if no true effect or } \\
\text { if underpowered. }\end{array}$ \\
\hline Hall [75] 2018 & $\begin{array}{l}\text { Randomised: Unclear; } \\
n=109 \text { recruited } \\
\text { Analysed } n=77 \\
(n=41 \text { dog; } n=36 \\
\text { no-treatment control) }\end{array}$ & HADS & $\begin{array}{l}\text { Mean change; calculation by } \\
\text { review } \\
\text { Anxiety (HADS anxiety): } \\
\text { Treatment:- }-2.68 \\
\text { No-treattent control: }-1.67 \\
\text { Independent } t \text {-test on pre- then } \\
\text { post-scores by authors } \\
\text { Depression (HADS depression): } \\
\text { non-normal distribution \& only } \\
\text { given mean; } \\
\text { Treatment:-0.93; No-treatment } \\
\text { control: }-1.55\end{array}$ & $\begin{array}{l}\text { Anxiety: } p=0.076 \text { (NS) } \\
\text { between pre-scores for control } \\
\& \text { dog. } p=0.008 \text { between } \\
\text { post-scores for control \& dog } \\
\text { Depression: NR (non-normal } \\
\text { distribution) }\end{array}$ & Overall weight: medium & $\begin{array}{l}\text { Anxiety: } \\
\text { Beneficial } \\
\text { Depression: } \\
\text { No effect }\end{array}$ & $\begin{array}{l}\text { A mixture of group/individual dog } \\
\text { AAA sessions with free interaction \& } \\
\text { numerous opportunities to interact } \\
\text { over 15-16 weeks, showed a } \\
\text { statistically significant reduction in } \\
\text { anxiety in favour of dogs on } \\
\text { post-score (not controlled for } \\
\text { pre-score; however, if evenly } \\
\text { randomised can be } \\
\text { appropriate [209]). } \\
\text { Caution: depression scores not } \\
\text { normally distributed (only means } \\
\text { provided personal communication } \\
\text { [81]). Appears to reduce in both } \\
\text { groups: more in control group. }\end{array}$ \\
\hline${ }_{2018}^{\text {Hunt }[76]}$ & $\begin{array}{l}\text { Randomised: } n=119 \\
\text { Analysed: Unclear regarding final } \\
\text { number analysed: } \\
\text { (study break with dog; } \\
\text { no-treatment controli; } \\
\text { mindfulness training alone; } \\
\text { yoga alone; } \\
\text { combined mindfulness \& } \\
\text { yoga training) }\end{array}$ & $\begin{array}{l}\text { STAI-S } \\
\text { PANAS positive } \\
\text { PANAS negative }\end{array}$ & $\begin{array}{l}\text { Mean change trends from baseline } \\
\text { to after 1st session reported as } \\
\text { relevant results only presented in } \\
\text { graphs. Authors only report } \\
\text { statistical results for after stressor. } \\
\text { Anxiety (STAI-S): } \\
\text { Treatment: reduction } \\
\text { No-treatment control: an increase } \\
\text { Positive mood (PANAS positive): } \\
\text { Means NR } \\
\text { Negative mood } \\
\text { (PANAS negative): } \\
\text { Treatment: reduction } \\
\text { No-treatment control: no change } \\
\text { Repeated measure ANOVA of } \\
\text { condition across time \& after each } \\
\text { time-point; then } \\
\text { pairwise comparisons }\end{array}$ & $\begin{array}{l}\text { Anxiety (dog vs. control): } \\
\text { No stressor: NS } p=0.07 \text { by } \\
\text { 4th session } \\
\text { Stressor: anxiety higher } p<0.05 \\
\text { Mood: } \\
\text { No stressor: PANAS positive: } \\
\text { NS; PANAS negative: control } \\
\text { worse mood over time than dog } \\
\text { group }(p \leq 0.01) \text {; but NS by } 4 \text { th } \\
\text { session. } \\
\text { Stressor: NS }(p<0.1)\end{array}$ & Overall weight: medium & $\begin{array}{l}\text { Anxiety: } \\
\text { Beneficial } \\
\text { Mood: } \\
\text { PANAS positive: } \\
\text { unable to assess } \\
\text { PANAS negative: } \\
\text { Beneficial }\end{array}$ & $\begin{array}{l}\text { Group AAA sessions with free } \\
\text { interaction of NR length once a week } \\
\text { for } 4 \text { weeks with a dog (with games, } \\
\text { icebreakers \& snacks) demonstrated: } \\
\text { (1) anxiety levels reduced for dog } \\
\text { group compared to control } \\
\text { (statistical significance only reported } \\
\text { for 4th session = NS) } \\
\text { (2) Control had statistically } \\
\text { significant worse negative mood } \\
\text { over time compared to dog group } \\
\text { but not by 4th session } \\
\text { After a stressor (1-3 weeks after } \\
\text { interventions had finished), dog } \\
\text { group had statistically significant } \\
\text { worsening of anxiety levels \& NS } \\
\text { higher negative mood compared to } \\
\text { control. Positive mood was NR. } \\
\text { Where NS , no power calculation so } \\
\text { unable to say if no true effect or } \\
\text { if underpowered. }\end{array}$ \\
\hline Meola [80] 2017 & $\begin{array}{l}\text { Randomised: } n=20 \\
\text { Analysed: } n=19 \text { (unclear split } \\
\text { between EALS \& control) }\end{array}$ & STAI-S & $\begin{array}{l}\text { Mean change; calculation by } \\
\text { review } \\
\text { Anxiety (STAI): } \\
\text { Treatment: -0.16 } \\
\text { No-treattent control: } 0.09 \\
\text { Split plot MANOVA for pre- \& } \\
\text { post-test }\end{array}$ & $\begin{array}{l}\text { Anxiety: } \\
p=0.274 \text { (NS) }\end{array}$ & Overall weight: medium & $\begin{array}{l}\text { Anxiety: } \\
\text { Beneficial }\end{array}$ & $\begin{array}{l}\text { Individual 1-h structured AAT/AAE } \\
\text { session with a horse demonstrated a } \\
\text { small reduction in anxiety when } \\
\text { measured up to } 1 \text { month after } \\
\text { intervention (NS but underpowered). }\end{array}$ \\
\hline
\end{tabular}


Table A3. Cont.

\begin{tabular}{|c|c|c|c|c|c|c|c|}
\hline Author \& Year & Sample Size & Outcome & $\begin{array}{l}\text { Findings with Effect Measures \& } \\
\text { Statistical Test Used by Authors }\end{array}$ & $p$ Value & $\begin{array}{l}\text { Evidence } \\
\text { Strength }\end{array}$ & Vote Count & Conclusions \\
\hline $\begin{array}{c}\text { Shearer } \\
{[77]} \\
2016\end{array}$ & $\begin{array}{l}\text { Randomised: } n=74 \\
\text { Analysed: Numbers analysed vary } \\
\text { at each time-point: 'destress with } \\
\text { dog', ino-trateatment control; } \\
\text { mindfulness meditation }\end{array}$ & $\begin{array}{l}\text { STAI-S } \\
\text { BDI II }\end{array}$ & 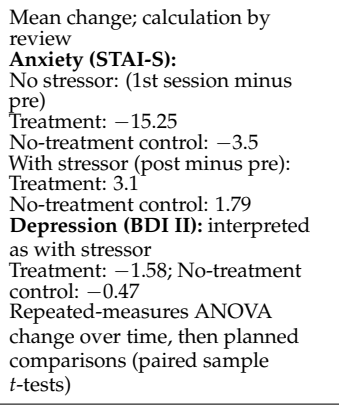 & $\begin{array}{l}\text { Anxiety: } \\
\text { No stressor: control } \\
\text { significantly different }(p=\text { NR) } \\
\text { across time for anxiety when } \\
\text { compared to dog group. } \\
\text { Stressor: NS } \\
\text { Depression: } \\
\text { No stressor NR } \\
\text { Stressor: NS }\end{array}$ & Overall weight: low & $\begin{array}{l}\text { Anxiety: } \\
\text { Beneficial } \\
\text { Depression: } \\
\text { Beneficial }\end{array}$ & $\begin{array}{l}\text { Group free interaction AAA sessions } \\
\text { with a dog including games \& snacks } \\
\text { lasting for } 1 \mathrm{~h} / \text { week for } 4 \text { weeks had } \\
\text { statisticilly significant lower anxiety } \\
\text { scores than control. } \\
\text { After a stressor (1-2 weeks after } \\
\text { interventions finished), anxiety } \\
\text { levels increased in both groups but } \\
\text { greater in treatment group (NS). } \\
\text { Depression scores decreased in both } \\
\text { groups with treatment group } \\
\text { reducing more (NS) than control. } \\
\text { Where NS, no power calculation so } \\
\text { unable to say if no true effect or } \\
\text { if underpowered. }\end{array}$ \\
\hline $\begin{array}{l}\text { Ward-Griffin [78] } \\
2018\end{array}$ & $\begin{array}{l}\text { Randomised: } n=357 \\
\text { Analysed: } n=246 \\
(n=122 \text { dog; } \\
n=124 \text { wait-list control) }\end{array}$ & $\begin{array}{l}\text { PSS } \\
\text { PANAS positive } \\
\text { PANAS negative } \\
\text { SWLS nebjective Happiness Scale } \\
\text { Subedical Outcomes Social } \\
\text { Medical } \\
\text { Support }\end{array}$ & 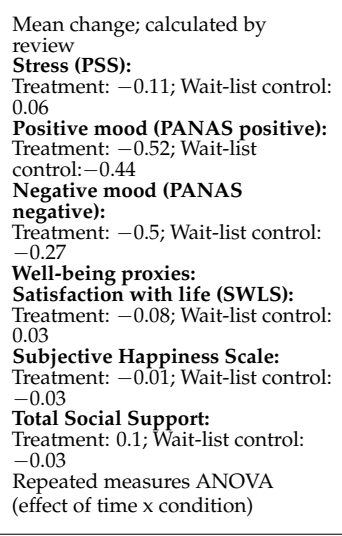 & $\begin{array}{l}\text { Effect of time } x \text { condition } \\
p=0.007 \text { negative mood; } \\
p=0.31 \text { stress } \\
p=0.032 \text { total social support } \\
\text { (gender as a fixed factor no } \\
\text { significant interaction between } \\
\text { condition, time \& gender) } \\
p \text { values otherwise NS }\end{array}$ & Overall weight: medium & $\begin{array}{l}\text { Stress: } \\
\text { Beneficial } \\
\text { Mood positive: } \\
\text { Detrimental } \\
\text { Mood negative: } \\
\text { Beneficial } \\
\text { Well-being: } \\
\text { SWLS: } \\
\text { Detrimental } \\
\text { Happiness: No effect } \\
\text { Total Social Support: } \\
\text { Beneficial }\end{array}$ & $\begin{array}{l}\text { Group free interaction single AAA } \\
\text { session with dogs lasting up to } \\
90 \text { min with outcomes measured up } \\
\text { to } 24 \text { h after delivery, had statistically } \\
\text { significant reduction in stress, } \\
\text { negative mood \& amelioration of } \\
\text { total social support compared to } \\
\text { control. } \\
\text { Positive mood reduced for both } \\
\text { grousp \& slightly more in treatment } \\
\text { group (NS). } \\
\text { Well-being: Satisfaction with Life: } \\
\text { both groups were in the extremely } \\
\text { dissatisfied category at baseline. } \\
\text { Scores reduced in dog (NS) \& did not } \\
\text { change category. Happiness levels } \\
\text { essentially did not change. Total } \\
\text { social support significantly increased } \\
\text { in treatment group. } \\
\text { Where NS, no power calculation so } \\
\text { unable to say if no true effect or if } \\
\text { underpowered. }\end{array}$ \\
\hline$\underset{2018}{\text { Williams [79] }}$ & $\begin{array}{l}\text { Randomised: } n=39 \\
\text { Analysed: } n=37(n=19 \text { dog \& } \\
n=18 \text { no-treatment control } \\
\text { e.g., studying) }\end{array}$ & STAI-S\&T & $\begin{array}{l}\text { Mean change; calculation by } \\
\text { review } \\
\text { Anxiety (STAI-S\&T): } \\
\text { Treatment: } 2.95 \\
\text { No-treatment control: } 16.33 \\
\text { 2-way mixed ANOVA, } \\
\text { independent } t \text {-tests \& Wilcoxon } \\
\text { signed rank }\end{array}$ & $\begin{array}{l}\text { Anxiety: } \\
p=0.008 \text { control had more } \\
\text { anxiety than treatment group } \\
\text { on exam day }\end{array}$ & Overall weight: medium & $\begin{array}{l}\text { Anxiety } \\
\text { (with stressor): } \\
\text { Beneficial }\end{array}$ & $\begin{array}{l}\text { For a 12-min inferred individual } \\
\text { single AAA session delivered prior } \\
\text { to an exam, anxiety levels increased } \\
\text { for both groups with control having } \\
\text { statistically significant higher levels } \\
\text { of anxiety than dog. }\end{array}$ \\
\hline
\end{tabular}




\section{References}

1. Thorley, C. Not by Degrees: Not by Degrees: Improving Student Mental Health in UK's Universities; IPPR: London, UK, 2017; Available online: https: / / www.ippr.org/publications/not-by-degrees (accessed on 2 February 2020).

2. Bell, A. Paws for a Study Break: Running an Animal-Assisted Therapy Program at the Gerstein Science Information Centre. Partnership Can. J. Libr. Inf. Pr. Res. 2013, 8, 1. [CrossRef]

3. Hughes, G.; Spanner, L. The University Mental Health Charter; Student Minds: Leeds, UK, 2019.

4. Bethlehem, J. Applied Survey Methods: A Statistical Perspective Applied Survey Methods. 2009. Available online: http: / / www.applied-survey-methods.com/weight.html (accessed on 22 July 2020).

5. Campbell, D. UK students waiting up to three months for mental health care. Guardian 2019, 11, 243.

6. Crossman, M.K.; Kazdin, A.E. Animal visitation programs in colleges and universities: An efficient mode for reducing student stress. In Handbook on Animal-Assisted Therapy: Foundations and Guidelines for Animal-Assisted Interventions, 4th ed.; Fine, A.H., Ed.; Elsevier Science \& Technology: Alpharetta, GA, USA, 2015; pp. 333-337.

7. American Veterinary Medical Association (AVMA). Animal-assisted interventions: Definitions. 2020. Available online: https: //www.avma.org/policies/animal-assisted-interventions-definitions (accessed on 26 January 2020).

8. International Association of Human-Animal Interaction (IAHAIO). The IAHAIO Definitions for Animal-Assisted Intervention and Guidelines for Wellness of Animals Involved in AAIs. 2018. Available online: https://iahaio.org/wp/wp-content/uploads/ 2018/04/iahaio_wp_updated-2018-final.pdf (accessed on 4 May 2020).

9. The Society for Companion Animal Studies (SCAS). Animal Assisted Interventions: SCAS Code of Practice for the UK. 2019. Available online: http:/ / www.scas.org.uk/wp-content/uploads/2019/08/SCAS-AAI-Code-of-Practice-August-2019.pdf (accessed on 5 May 2020).

10. Kamioka, H.; Okada, S.; Tsutani, K.; Park, H.; Okuizumi, H.; Handa, S.; Oshio, T.; Park, S.-J.; Kitayuguchi, J.; Abe, T.; et al. Effectiveness of animal-assisted therapy: A systematic review of randomized controlled trials. Complement. Ther. Med. 2014, 22, 371-390. [CrossRef]

11. Nimer, J.; Lundahl, B. Animal-Assisted Therapy: A Meta-Analysis. Anthrozoös 2007, 20, 225-238. [CrossRef]

12. Bert, F.; Gualano, M.R.; Camussi, E.; Pieve, G.; Voglino, G.; Siliquini, R. Animal assisted intervention: A systematic review of benefits and risks. Eur. J. Integr. Med. 2016, 8, 695-706. [CrossRef] [PubMed]

13. Brelsford, V.L.; Meints, K.; Gee, N.R.; Pfeffer, K. Animal-Assisted Interventions in the Classroom-A Systematic Review. Int. J. Environ. Res. Public Health 2017, 14, 669. [CrossRef] [PubMed]

14. Shen, R.Z.; Xiong, P.; Chou, U.I.; Hall, B.J. "We need them as much as they need us": A systematic review of the qualitative evidence for possible mechanisms of effectiveness of animal-assisted intervention (AAI). Complement. Ther. Med. 2018, 41, 203-207. [CrossRef] [PubMed]

15. Morrison, M.L. Health Benefits of Animal-Assisted Interventions. Complement. Health Pr. Rev. 2007, 12, 51-62. [CrossRef]

16. Odendaal, J.; Meintjes, R. Neurophysiological Correlates of Affiliative Behaviour between Humans and Dogs. Veter-J. 2003, 165, 296-301. [CrossRef]

17. Polheber, J.P.; Matchock, R.L. The presence of a dog attenuates cortisol and heart rate in the Trier Social Stress Test compared to human friends. J. Behav. Med. 2014, 37, 860-867. [CrossRef]

18. Stasi, M.; Amati, D.; Costa, C.; Resta, D.; Senepa, G.; Scarafioiti, C.; Aimonino, N.; Molaschi, M. Pet-therapy: A trial for institutionalized frail elderly patients. Arch. Gerontol. Geriatr. 2004, 38, 407-412. [CrossRef]

19. Lai, N.M.; Chang, S.M.W.; Ng, S.S.; Tan, S.L.; Chaiyakunapruk, N.; Stanaway, F. Animal-assisted therapy for dementia. Cochrane Database Syst. Rev. 2019, 11. [CrossRef]

20. Ein, N.; Li, L.; Vickers, K. The effect of pet therapy on the physiological and subjective stress response: A meta-analysis. Stress Health 2018, 34, 477-489. [CrossRef]

21. Crump, C.; Derting, T.L. Effects of pet therapy on the psychological and physiological stress levels of first-year female undergraduates. N. Am. J. Psychol. 2015, 17, 575-590.

22. Beck, A.M. The biology of the human-animal bond. Anim. Front. 2014, 4, 32-36. [CrossRef]

23. Bartley, M. Health Inequalities: An Introduction to Theories, Concepts and Methods, 2nd ed.; Blackwell Publishing Ltd.: Cambridge, UK, 2004.

24. Cobb, S. Social Support as a Moderator of Life Stress. Psychosom. Med. 1976, 38, 300-314. [CrossRef]

25. Fine, A.H.; Beck, A.M. Understanding Our Kinship with Animals: Input for Health Care Professionals Interested in the HumanAnimal Bond. In Handbook on Animal-Assisted Therapy: Foundations and Guidelines for Animal-Assisted Interventions, 4th ed.; Fine, A.H., Ed.; Elsevier Science \& Technology: Philadelphia, PA, USA, 2015; pp. 3-10.

26. Wilson, E. Biophilia: The Human Bond with Other Species; Harvard University Press: Cambridge, MA, USA, 1986.

27. Hudson, B.; Ogden, J.; Whiteley, M. Randomized controlled trial to compare the effect of simple distraction interventions on pain and anxiety experienced during conscious surgery. Eur. J. Pain 2015, 19, 1447-1455. [CrossRef]

28. Newcastle University. Bessie Gives Students Time to Paws for Thought; Newcastle University Press Office. 2019. Available online: https:/ / www.ncl.ac.uk/press/articles/latest/2019/10/borrowbessie/ (accessed on 28 January 2020).

29. Spencer, C. Dogs help relieve Swansea students' exam stress. BBC News. 2019. Available online: https://www.bbc.co.uk/news/ uk-wales-47074779 (accessed on 5 May 2020). 
30. Coughlan, S. Stress-busting dogs on university staff. BBC News. 2019. Available online: https://www.bbc.co.uk/news/ education-48097050 (accessed on 5 May 2020).

31. University of Sheffield. Pet Therapy Day 2018. 2018. Available online: https://www.sheffield.ac.uk/sss/news/pet-therapy-2018 -1.804532 (accessed on 5 May 2020).

32. Newcastle University. Wellbeing Initiatives: Borrow Bessie. 2020. Available online: https://www.ncl.ac.uk/wellbeing/ newseventsandprojects/initiatives/\#borrowbessie (accessed on 11 May 2020).

33. Reynolds, J.A.; Rabschutz, L. Studying for Exams Just Got More Relaxing-Animal-Assisted Activities at the University of Connecticut Library. Coll. Undergrad. Libr. 2011, 18, 359-367. [CrossRef]

34. Daltry, R.M.; Mehr, K.E. Therapy Dogs on Campus: Recommendations for Counseling Center Outreach. J. Coll. Stud. Psychother. 2015, 29, 72-78. [CrossRef]

35. Binfet, J.-T. The Effects of Group-Administered Canine Therapy on University Students' Wellbeing: A Randomized Controlled Trial. Anthrozoös 2017, 30, 397-414. [CrossRef]

36. Crossman, M.K.; Kazdin, A.E.; Knudson, K. Brief Unstructured Interaction with a Dog Reduces Distress. Anthrozoös 2015, 28, 649-659. [CrossRef]

37. Grajfoner, D.; Harte, E.; Potter, L.M.; McGuigan, N. The Effect of Dog-Assisted Intervention on Student Well-Being, Mood, and Anxiety. Int. J. Environ. Res. Public Health 2017, 14, 483. [CrossRef] [PubMed]

38. Parbery-Clark, C.; McColl, E.; Tanner, L. Animal-Assisted Interventions for the Improvement of Mental Health Outcomes in Higher Education Students: Prospero Form. 2020. Available online: https:/ /www.crd.york.ac.uk/prospero/display_record.php? RecordID $=186541$ (accessed on 26 June 2020).

39. Moher, D.; Liberati, A.; Tetzlaff, J.; Altman, D.G. Preferred Reporting Items for Systematic Reviews and Meta-Analyses: The PRISMA statement. PLoS Med. 2009, 6, e1000097. [CrossRef]

40. Higgins, J.P.T.; Thomas, J.; Chandler, J.; Cumpston, M.; Page, M.J.; Welch, V.A. Cochrane Handbook of Systematic Reviews of Interventions, 2nd ed.; John Wiley \& Sons: Chichester, UK, 2019.

41. Cummins, I. The Impact of Austerity on Mental Health Service Provision: A UK Perspective. Int. J. Environ. Res. Public Health 2018, 15, 1145. [CrossRef]

42. Hart, L.A.; Yamamoto, M. Recruiting Psychosocial Health Effects of Animals for Families and Communities: Transition to Practice. In Handbook on Animal-Assisted Therapy: Foundations and Guidelines for Animal-Assisted Interventions, 4th ed.; Fine, A.H., Ed.; Elsevier Science \& Technology: Philadelphia, PA, USA, 2015; pp. 53-72.

43. American Veterinary Medical Association (AVMA). Service Animals. 2020. Available online: https://www.avma.org/resourcestools/avma-policies/service-animals (accessed on 15 July 2020).

44. The Society for Companion Animal Studies (SCAS). Therapy/Assistance Dogs. 2013. Available online: http:/ /www.scas.org.uk/ animal-assisted-interventions/therapy-assistance-dogs / (accessed on 15 July 2020).

45. American Veterinary Medical Association (AVMA). Service, Emotional Support and Therapy Animals. 2020. Available online: https: / / www.avma.org/resources-tools/animal-health-welfare/service-emotional-support-and-therapy-animals (accessed on 15 July 2020).

46. Department for Education. Further Education Courses and Funding. 2020. Available online: https://www.gov.uk/furthereducation-courses (accessed on 21 June 2020).

47. Animal Assisted Intervention International (AAII). Animal Assisted Intervention International Standards of Practice: Animal Assisted Intervention International (AAII). 2019. Available online: https://aai-int.org/wp-content/uploads/2019/02/AAIIStandards-of-Practice.pdf (accessed on 4 May 2020).

48. Animal Assisted Intervention International (AAII). Animal Assisted Intervention. 2020. Available online: https://aai-int.org/ aai/animal-assisted-intervention/ (accessed on 24 April 2020).

49. Santaniello, A.; Die, F.; Carratu, R.C.; Amato, A.; Fioretti, A.; Menna, L.F. Methodological and terminalogical issues in animalassisted interventions: An umbrella reviews of systematic reviews. Animals 2020, 10, 759. [CrossRef] [PubMed]

50. Horn, B.; Balk, J.; Gold, J.I. Revisiting the Sham: Is It all Smoke and Mirrors? Evidence-Based Complement. Altern. Med. 2011, 2011, 842767. [CrossRef]

51. Spielberger, C.D.; Gorsuch, R.L.; Lushene, R.; Vagg, P.R.; Jacobs, G.A. Manual for the State-Trait Anxiety Inventory; CPP Press: Palo Alto, CA, USA, 1983.

52. Cohen, S.; Kamarck, T.; Mermelstein, R. A global measure of perceived stress. J. Health Soc. Behav. 1983, 24, 386-396. [CrossRef]

53. Nightline Association. Depressed, Anxious, Lonely and Homesick: Study Reveals Darker Side to Student Life. 2013. Available online: https:/ / www.nightline.ac.uk/2013/06/depressed-anxious-lonely-and-homesick-study-reveals-darker-side-to-studentlife/ (accessed on 11 May 2020).

54. The Insight Network. University Student Mental Health Survey 2018, London. 2019. Available online: https://uploads-ssl. webflow.com/561110743bc7e45e78292140/5c7d4b5d314d163fecdc3706_Mental\%20Health\%20Report\%202018.pdf (accessed on 15 January 2020).

55. The Insight Network. University Student Mental Health Survey 2020, London. 2020. Available online: https://www.diginbox. com/go/files/Mental\%20Health\%20Report\%202019.pdf (accessed on 11 May 2020). 
56. Anxiety and Depression Association of America (ADAA). Understanding the Facts: Stress: Anxiety and Depression Association of America (ADAA). 2018. Available online: https://adaa.org/understanding-anxiety/related-illnesses/stress (accessed on 24 April 2020).

57. Tennant, R.; Hiller, L.; Fishwick, R.; Platt, S.; Joseph, S.; Weich, S.; Parkinson, J.; Secker, J.; Stewart-Brown, S. The WarwickEdinburgh Mental Well-being Scale (WEMWBS): Development and UK validation. Health Qual. Life Outcomes $2007,5,63$. [CrossRef] [PubMed]

58. Watson, D.; Clark, L.A.; Tellegen, A. Development and validation of brief measures of positive and negative affect: The PANAS scales. J. Pers. Soc. Psychol. 1988, 54, 1063-1070. [CrossRef]

59. Akobeng, A.K. Understanding randomised controlled trials. Arch. Dis. Child. 2005, 90, 840-844. [CrossRef]

60. Petticrew, M.; Roberts, H. Systematic Reviews in the Social Sciences: A Practical Guide; Blackwell LTD.: Oxford, UK, 2006.

61. Ouzzani, M.; Hammady, H.; Fedorowicz, Z.; Elmagarmid, A. Rayyan-A web and mobile app for systematic reviews. Syst. Rev. 2016, 5, 210. [CrossRef] [PubMed]

62. Haar, M. Random.org: Randomness and Integrity Services Ltd. 1998. Available online: https://www.random.org/analysis/ (accessed on 29 May 2020).

63. Grossetta Nardini, H.K.; Wang, L. The Yale MeSH Analyzer; Internet; Cushing/Whitney Medical Library: New Haven, CT, USA, 2017; Available online: http:/ / mesh.med.yale.edu/ (accessed on 17 March 2020).

64. Reuters, T. Endnote X9 Thomson Reuters. J. Electron. Resour. Med Libr. 2019, 10, 1691963.

65. Hoffman, T.; Glasziou, P.; Milne, R.; Perera, R.; Moher, D.; Altman, D.G.; Barbour, V.; Macdonald, H.; Johnston, M.; Lamb, S.E. Better reporting of interventions: Template for intervention description and replication (TIDieR) checklist and guide. BMJ 2014, 348, g1687. [CrossRef]

66. Whiting, P.; Savovic, J.; Higgin, J.; Caldwell, D.; Reeves, B.; Shea, B.; Davies, P.; Kleijnen, J.; Churchill, R. Robis: Tool to Assess Risk of Bias in Systematic Reviews-Guidance on How to Use ROBIS. 2015. Available online: https://www.bristol.ac.uk/medialibrary/sites/social-community-medicine/robis/robisguidancedocument.pdf (accessed on 1 January 2020).

67. Sterne, J.A.C.; Savović, J.; Page, M.J.; Elbers, R.G.; Blencowe, N.S.; Boutron, I.; Cates, C.J.; Cheng, H.-Y.; Corbett, M.S.; Eldridge, S.M.; et al. RoB 2: A revised tool for assessing risk of bias in randomised trials. BMJ 2019, 366, 14898. [CrossRef]

68. RoB2 Development Group. Revised Cochrane Risk-of-Bias Tool for Randomized Trials (RoB2). 2019. Available online: https: // methods.cochrane.org/bias/resources/rob-2-revised-cochrane-risk-bias-tool-randomized-trials (accessed on 24 April 2020).

69. Popay, J.; Roberts, H.; Sowden, A.; Petticrew, M.; Arai, L.; Rodgers, M.; Britten, N.; Roen, K.; Duffy, S. Guidance on the conduct of narrative synthesis in systematic reviews. In A Product from the ESRC Methods Programme; Lancaster Universit: Lancaster, UK, 2006. [CrossRef]

70. Gough, D. Weight of Evidence: A framework for the appraisal of the quality and relevance of evidence. Res. Pap. Educ. 2007, 22, 213-228. [CrossRef]

71. Jadad, A.R.; Moore, R.A.; Carroll, D.; Jenkinson, C.; Reynolds, D.J.; Gavaghan, D.J.; McQuay, H.J. Assessing the quality of reports of randomized clinical trials: Is blinding necessary? Control. Clin. Trials 1996, 17, 1-12. [CrossRef]

72. Banks, J.B.; McCoy, C.; Trzcinski, C. Examining the impact of a brief human-canine interaction on stress and attention. Hum.-Anim. Interact. Bull. 2018, 6, 1.

73. Fiocco, A.J.; Hunse, A.M. The Buffer Effect of Therapy Dog Exposure on Stress Reactivity in Undergraduate Students. Int. J. Environ. Res. Public Health 2017, 14, 707. [CrossRef]

74. Gebhart, V.; Buchberger, W.; Klotz, I.; Neururer, S.; Rungg, C.; Tucek, G.; Zenzmaier, C.; Perkhofer, S. Distraction-focused interventions on examination stress in nursing students: Effects on psychological stress and biomarker levels. A randomized controlled trial. Int. J. Nurs. Pr. 2019, 26, e12788. [CrossRef]

75. Hall, D. Nursing Campus Therapy Dog: A Pilot Study. Teach. Learn. Nurs. 2018, 13, 202-206. [CrossRef]

76. Hunt, M.; Al-Braiki, F.; Dailey, S.; Russell, R.; Simon, K. Mindfulness Training, Yoga, or Both? Dismantling the Active Components of a Mindfulness-Based Stress Reduction Intervention. Mindfulness 2018, 9, 512-520. [CrossRef]

77. Shearer, A.; Hunt, M.; Chowdhury, M.; Nicol, L. Effects of a brief mindfulness meditation intervention on student stress and heart rate variability. Int. J. Stress Manag. 2016, 23, 232-254. [CrossRef]

78. Ward-Griffin, E.; Klaiber, P.; Collins, H.K.; Owens, R.L.; Coren, S.; Chen, F.S. Petting away pre-exam stress: The effect of therapy dog sessions on student well-being. Stress Health 2018, 34, 468-473. [CrossRef]

79. Williams, C.; Emond, K.; Maynord, K.; Simpkins, J.; Stumbo, A.; Terhaar, T. An animal-assisted intervention's influence on graduate students' stress and anxiety prior to an examination. OALib 2018, 05, e4831. [CrossRef]

80. Meola, C. The Effects of an Equine Assisted Learning Supervision Intervention on Counselors'-in-Training Performance Anxiety, Counseling Self-Efficacy, and Supervisory Working Alliance. Ph.D. Thesis, East Carolina University, Greene County, NC, USA, 2017. Dissertation Abstracts International: Section B: The Sciences and Engineering.

81. Hall, D. Nursing campus therapy dog: A pilot study. Sci. Driect 2018, 5, 142. [CrossRef]

82. Higgins, J.; Green, S. Cochrane Handbok for Systematic Reviews of Interventions; John Wiley and Sons: Chichester, UK, 2016.

83. de Bruin, M. Risk of bias in randomised controlled trials of health behaviour change interventions: Evidence, practices and challenge. Psychol. Health 2015, 20, 1-7. [CrossRef] [PubMed]

84. Barratt, H.; Kirwan, M.; Shantikumar, S. Biases and Confounding: Health Knowledge. 2018. Available online: https://www. healthknowledge.org.uk/public-health-textbook/research-methods/1a-epidemiology/biases (accessed on 24 July 2020). 
85. Gosall, N.; Gosall, G. The Doctor's Guide to Critical Appraisal, 4th ed.; Pastest Ltd.: Cheshire, UK, 2015.

86. O’Haire, M.E.; Guérin, N.A.; Kirkham, A.C. Animal-Assisted Intervention for trauma: A systematic literature review. Front. Psychol. 2015, 6, 1121. [CrossRef] [PubMed]

87. Walmsley, A.L.E.; Brown, M.C. What is power? Statistics Teacher. 2017. Available online: https://www.statisticsteacher.org/2017 /09/15/what-is-power/ (accessed on 24 July 2020).

88. Fogg, B.J. A behavior model for persuasive design-Persuasive 09. In Proceedings of the 4th International Conference on Persuasive Technology, Claremont, CA, USA, 26-29 April 2009; pp. 1-7.

89. Moore, G.F.; Audrey, S.; Barker, M.; Bond, L.; Bonell, C.; Hardeman, W.; Moore, L.; O'Cathain, A.; Tinati, T.; Wight, D.; et al. Process evaluation of complex interventions: Medical Research Council guidance. BMJ 2015, 350, h1258. [CrossRef]

90. Craig, P.; Dieppe, P.; Macintyre, S.; Michie, S.; Nazareth, I.; Petticrew, M. Developing and evaluating complex interventions: The new Medical Research Council guidance. BMJ 2008, 337, a1655. [CrossRef] [PubMed]

91. Campbell, M.; Fitzpatrick, R.; Haines, A.; Kinmonth, A.L.; Sandercock, P.; Spiegelhalter, D.; Tyrer, P. Framework for design and evaluation of complex interventions to improve health. BMJ 2000, 321, 694-696. [CrossRef] [PubMed]

92. Bonell, C.; Jamal, F.; Melendez-Torres, G.; Cummins, S. 'Dark logic': Theorising the harmful consequences of public health interventions. J. Epidemiol. Community Health 2015, 69, 95-98. [CrossRef]

93. Adamle, K.N.; Riley, T.A.; Carlson, T. Evaluating college interest in pet therapy. J. Am. Coll. Health. 2009, 57, 545-548. [CrossRef]

94. Adams, A.C.; Sharkin, B.S.; Bottinelli, J.J. The role of pets in the lives of college students: Implications for college counsellors. J. College Stud. Psychother. 2017, 31, 306-324. [CrossRef]

95. Adams, T.; Clark, C.; Crowell, V.; Duffy, K.; Green, M. The mental health benefits of having dogs on college campuses. Mod. Psychol. 2017, 22, 7 .

96. Alonso, Y. Effects of pets on human health: Is there a correlation? Gesundheitswesen 1999, 61, 45-49. [PubMed]

97. Anderson, D. The Effect of Animal-Assisted Therapy on Nursing Student Anxiety. Ph.D. Thesis, University of Kansas, Lawrence, KS, USA, 2018. Dissertation Abstracts International Section: Humanities and Social Sciences.

98. Anonymous. DM-style program caters to behavioral needs of college students. Dis Manag Advis. 2004, 10, 55-56.

99. Anonymous. Dog therapy helps reduce stress in students. Vet. Rec. 2019, 184, 541. [CrossRef]

100. Ashton, L. Intrigued about equine modalities. J. Psychosoc. Nurs. Ment. Health Serv. 2011, 49, 16. [CrossRef]

101. Baghain, N.; Sari, A.A.; Shati, M.; Fallahzadeh, H. Evaluation of students' mental and social health promotion educational programs: A systematic review. J. Edu. Health Promot. 2019, 8, 258. [CrossRef]

102. Bajorek, K. The effects of pet therapy on undergraduate nursing students' perceived stress and exam performance. Honors Thesis, Western Michigan University, Kalamazoo, MI, USA, 2014.

103. Barker, S.; Barker, T.; McCain, N.L.; Schubert, C.M. A randomized cross-over exploratory study of the effect of visiting therapy dogs on college student stress before final exams. Anthrozoös 2016, 29, 35-46. [CrossRef]

104. Barker, S.; Barker, R.T.; McCain, N.L.; Schubert, C.M. The effect of a canine-assisted activity on college student perceptions of family supports and current stressors. Anthrozoös 2017, 30, 595-606. [CrossRef]

105. Barker, S.; Barker, R.T.; Schubert, C. Therapy dogs on campus: A counseling outreach activity for college students preparing for final exams. J. Coll. Couns. 2017, 20, 278-288. [CrossRef]

106. Barlow, R.; DeMarni Cromer, L.; Caron, H.P.; Freyd, J.J. Comparison of normative and diagnosed dissociation on attachment to companion animals and stuffed animals. Psychol Trauma. 2012, 4, 501-506. [CrossRef]

107. Basil, B.; Mathews, M. Human and animal health: Strengthening the link-Methodological concerns about animal facilitated therapy with dolphins. BMJ 2005, 331, 1407. [CrossRef] [PubMed]

108. Behnke, M.; Olson, S. Knowing is half the battle. Lab. Anim. 2019, 48, 69-70. [CrossRef]

109. Beutler, L.E.; Crago, M. Psychotherapy Research: An International Review of Programmatic Studies; American Psychological Association: Washington, DC, USA, 1991.

110. Biery, M.J. Riding and the handicapped. Vet. Clin. N. Am. Small Anim. Pract. 1985, 15, 345-354. [CrossRef]

111. Binfet, J.-T.; Passmore, H.-A. Hounds and homesickness: The effects of an animal-assisted therapeutic intervention for first-year university students. Anthrozoös 2016, 29, 441-454. [CrossRef]

112. Binfet, J.-T.; Passmore, H.-A.; Cebry, A.; Struik, K.; Mckay, C. Reducing university students' stress through a drop-in caninetherapy program. J. Ment. Health. 2018, 27, 197-204. [CrossRef]

113. Binfet, J.-T.; Trotman, M.L.; Henstock, H.D.; Silas, H. J Reducing the affective filter: Using Canine Assisted Therapy to support international university students' English language development. BC TEAL J. 2016, 1, 18. [CrossRef]

114. Bjick, M. The Effects of a Therapy Animal on College Student Stress and Arousal. In Social Work Master's Clinical Research Paper; St Catherine University \& University of St. Thomas: St. Paul, MN, USA, 2013.

115. Blender, J.A. A Multimodal Investigation of the Use of Animal-Assisted Therapy in a Clinical Interview. Ph.D. Thesis, University of Rochester, Rochester, NY, USA, 2010. Dissertation Abstracts International: Section B: The Sciences and Engineering.

116. Broeyer, L.; Chanson, P.F.; Durrenberger, Y. Educational meetings: "crisis intervention". "Catastrophe ... that concerns me". Krankenpfl.—Soins Infirm. 1990, 83, 70-71.

117. Buttelmann, D.; Rompke, A.-K. Anxiety-reducing effect: Dog, fish and plant in direct comparison. Anthrozoös 2014, 27, 267-277. [CrossRef] 
118. Chakales, P.A.; Locklear, J.; Wharton, T. Medicine and Horsemanship: The Effects of equine-assisted activities and therapies on stress and depression in medical students. Cureus 2020, 12, e6896. [CrossRef]

119. Chramouleeswaran, S.; Russell, P.S. Complementary psychosocial interventions in child and adolescent psychiatry: Pet assisted therapy. Indian J. Psychol. Med. 2014, 36, 4-8. [CrossRef]

120. Cieslak, E.J. Animal-Assisted Therapy and the Development of an Early Working Alliance: The Use of Dogs in Therapy with Young Adults. Ph.D. Thesis, University of Wisconsin-Madison, Madison, WI, USA, 2001. Dissertation Abstracts International: Section B: The Sciences and Engineering.

121. ClinicalTrials.gov. National Library of Medicine. Identifier: NCT02758886. Pet Your Stress Away Study. 2016. Available online: https: / / clinicaltrialsgov/show / NCT02758886 (accessed on 31 July 2020).

122. ClinicalTrials.gov. National Library of Medicine. Identifier: NCT03704779. Effectiveness of a Multimodal Mindfulness Program to Alleviate Graduate Student Stress. 2018. Available online: https:/ / clinicaltrialsgov/show / NCT03704779 (accessed on 31 July 2020).

123. ClinicalTrials.gov. National Library of Medicine. Identifier: NCT03530943. Pet Partners for Promotion of Academic Life Skills. 2018. Available online: https:/ / clinicaltrialsgov / show / NCT03530943 (accessed on 31 July 2020).

124. ClinicalTrials.gov. National Library of Medicine. Identifier: NCT04200612. The Therapeutic Effects of Equine-Assisted Psychotherapy. 2019. Available online: https:/ / clinicaltrialsgov/show/NCT04200612 (accessed on 31 July 2020).

125. Colarelli, S.M.; McDonald, A.; Christensen, M.S.; Honts, C. A companion dog increases prosocial behavior in work groups. Anthrozoös. 2017, 30, 77-89. [CrossRef]

126. Coleman, J.A.; Green, B.; Garthe, R.C.; Worthington, E.L.; Barker, S.; Ingram, K.M. The Coleman Dog Attitude Scale (C-DAS): Development, refinement, validation, and reliability. Appl. Anim. Behav. Sci. 2016, 176, 77-86. [CrossRef]

127. Crago, L.; Leeder, J. Animal magic. University \& College Counselling. 2014. Available online: https:/ /17d8607e-a6ae-496b-96bd48b9899bdf1a.filesusr.com/ugd/f89e47_3f02c88da55949deb740c5dae5b72407.pdf (accessed on 31 July 2020).

128. Delgado, C.; Toukonen, M.; Wheeler, C. Effect of canine play interventions as a stress reduction strategy in college students. Nurse Educ. 2018, 43, 149-153. [CrossRef]

129. Dell, C.A.; Chalmers, D.; Gillett, J.; Rohr, B.; Nickel, C.; Campbell, L.; Hanoski, R.; Haguerud, J.; Husband, A.; Stephenson, C.; et al. PAWSing student stress: A pilot evaluation study of the St. John Ambulance Therapy Dog program on three university campuses in Canada. Can. J. Couns. Psychother. 2015, 49, 332-359.

130. Dhooper, M.K. Animal-Assisted Therapy: The Effects of the Presence of a Trained Therapy Dog on Group Anxiety Management Training. Ph.D. Thesis, University of South Dakota, Vermillion, SD, USA, 2003. Dissertation Abstracts International: Section B: The Sciences and Engineering.

131. Dluzynski, J.L. A Quantitative Assessment of Test Anxiety and Human-Animal Interaction in College Students. Psy.D. Dissertation, ProQuest Dissertations Publishing. Michigan School of Professional Psychology, Farmington Hills, MI, USA, 2017.

132. Duffey, T. Letter from the editor. J. Creat. Ment. Health. 2014, 9, 317. [CrossRef]

133. Flaherty, L.T. School-based interventions as part of the therapeutic alliance. Adolesc. Psychiatry. 2012, 2, $105-106$.

134. Folse, E.B.; Minder, C.C.; Aycock, M.J.; Santana, R.T. Animal-assisted therapy and depression in adult college students. Anthrozoös 1994, 7, 188-194. [CrossRef]

135. Frederick, K.E. Understanding the Impact of Equine-Assisted Learning on Levels of Hope in at-Risk Adolescents. Ph.D. Thesis, Baylor University, Waco, TX, USA, 2012. Dissertation Abstracts International Section A: Humanities and Social Sciences.

136. Frederick, K.E.; Ivey Hatz, J.; Lanning, B. Not Just Horsing Around: The Impact of Equine-Assisted Learning on Levels of Hope and Depression in At-Risk Adolescents. Community Ment. Health J. 2015, 51, 809-817. [CrossRef] [PubMed]

137. Friedmann, E.; Locker, B.Z.; Lockwood, R. Perception of animals and cardiovascular responses during verbalization with an animal present. Anthrozoös 1993, 6, 115-134. [CrossRef]

138. Gonzalez-Ramirez, M.T.; Landaverde-Molina, O.D.; Morales-Rodriguez, D.; Landero-Hernandez, R. Speech anxiety management workshop assisted by therapy dogs. Ansiedad y Estres. 2016, 22, 5-10.

139. Goodkind, J.; LaNoue, M.; Lee, C.; Freeland, L.; Freund, R. Feasibility, acceptability, and initial findings from a community-based cultural mental health intervention for American Indian youth and their families. J. Community Psychol. 2012, 40, $381-405$. [CrossRef] [PubMed]

140. Gress, K. Animals helping people. People helping animals. Interview by Shirley A. Smoyak. J. Psychosoc. Nurs. Ment. Health Serv. 2003, 41, 18-25.

141. Haggerty, J.; Mueller, M. Animal-assisted stress reduction programs in higher education. Innov. High. Educ. 2017, 42, 379-389. [CrossRef]

142. Hammer, C.J.; Bach-Gorman, A.R.; Berg, E.L. Equine-assisted counseling as an intervention for undergraduate female college students experiencing anxiety. J. Equine Vet Sc. 2019, 76, 118. [CrossRef]

143. Hemingway, A.; Carter, S.; Callaway, A.; Kavanagh, E.; Ellis, S. An exploration of the mechanism of action of an equine-assisted intervention. Animals 2019, 9, 303. [CrossRef]

144. Henry, C. The Psychological and Physiological Effects of Using a Therapy Dog in Mindfulness Training. Ph.D. Thesis, Utah State University, Logan, UT, USA, 2013.

145. House, L.A.; Neal, C.; Backels, K. A doggone way to reduce stress: An animal assisted intervention with college students. Coll. Stud. J. 2018, 52, 199-204. 
146. Ishimura, I.; Komazawa, A. Positive psychological resources among Japanese university students with deep depression and anxiety: A study of flow experience and strength-awareness. Int. J. Psychiatry Clin. Pract. 2012, 16, 30-31.

147. Jarolmen, J.; Patel, G. The effects of animal-assisted activities on college students before and after a final exam. J. Creat. Ment. Health. 2018, 13, 264-274. [CrossRef]

148. Johnson, R.A. Promoting one health: The University of Missouri Research Center for Human/Animal Interaction. Mo Med. 2013, 110, 197-200. [PubMed]

149. King, C.A. The Relationship between Human-Canine Attachment and College Adjustment. Ph.D. Thesis, Northern Illinois University, DeKalb, IL, USA, 2012. Dissertation Abstracts International Section A: Humanities and Social Sciences.

150. Kobayashi, A.; Yamaguchi, Y.; Ohtani, N.; Ohta, M. The effects of touching and stroking a cat on the inferior frontal gyrus in people. Anthrozoös 2017, 30, 473-486. [CrossRef]

151. Kronholz, J.F.; Freeman, V.F.; Mackintosh, R.C. Animal-Assisted Therapy: Best practices for college counseling. Ideas and Research You Can Use: VISTAS. 2015. Available online: https:/ /www.counseling.org/docs/default-source/vistas/article_7525 cd23f16116603abcacff0000bee5e7.pdf?sfvrsn=bbdb432c_8 (accessed on 31 July 2020).

152. Kuzara, S.; Pendry, P.; Gee, N.R. Exploring the handler-dog connection within a university-based Animal-Assisted Activity. Animals 2019, 9, 402. [CrossRef] [PubMed]

153. Lacoff, S.L.; Boris, M. Levinson: A Historical Perspective. A Focus on His Work Involving Animal-Assisted Psychotherapy. Doctoral Thesis, Miami Institute of Psychology, Miami, FL, USA, 1999. Dissertation Abstracts International: Section B: The Sciences and Engineering.

154. Lauriente, T.; Kopp, D. Therapy Dogs on Campus: An Exploration of How Dog Therapy Services Affect Undergraduate Students' Stress Levels. Ph.D. Thesis, Thompson River's University, Kamloops, BC, Canada, 2018.

155. Lephart, S.P.; Jennings, C.; Hamilton, A.N.C.; Hoellein, A.R. The paws that refresh us: Can animal-assisted therapy have an effect on exam performance in medical students? Glob. Adv. Health Med. 2018, 7, 203-204.

156. Linden, M. Recognition and treatment of work-related anxieties. Psychother. Psychosom. 2013, 82, $56-57$.

157. Litwiller, F.; White, C.; Hamilton-Hinch, B.; Gilbert, R. The impacts of recreation programs on the mental health of postsecondary students in North America: An integrative review. Leis. Sci. 2018. [CrossRef]

158. Machova, K.; Prochazkova, R.; Vadronova, M.; Souckova, M.; Prouzova, E. Effect of dog presence on stress levels in students under psychological strain: A pilot study. IJERPH 2020, 17, 2286. [CrossRef]

159. Malakoff, M. Effects of Animal-Assisted Therapy on Students with Emotional and Behavioral Disorders. Ph.D. Thesis, Alliant International University, San Diego, CA, USA, 2009. Dissertation Abstracts International: Section B: The Sciences and Engineering.

160. Manor, W. Directions for the human-animal bond in the nursing education curriculum. Holist. Nursing Prac. 1991, 5, 64-71. [CrossRef]

161. Marino, L. Construct Validity of Animal-Assisted Therapy and Activities: How Important Is the Animal in AAT? Anthrozoös 2012, 25, s139-s151. [CrossRef]

162. Matsuura, A.; Nagai, N.; Funatsu, A.; Irimajiri, M.; Yamazaki, A.; Hodate, K. Comparison of the short-term effects of horse trekking \& exercising with a riding simulator on autonomic nervous activity. Anthrozoös 2011, 24, 65-77.

163. McArthur, A.D.; Syrnyk, C. On-campus animal-assisted therapy events: Post-secondary students' reactions and mood. Soc. Anim. J. Hum. Anim. Stud. 2018, 26, 616-632. [CrossRef]

164. McCrindle, C.M. Companion animal health education programmes in schools. J. S. Afr. Vet. Assoc. 1996, 67, 102.

165. McDonald, S.; McDonald, E.; Roberts, A. Effects of novel dog exposure on college students' stress prior to examination. North Am. J. Psycho. 2017, 19, 477-484.

166. Merritt, A.E. The effect of a Structured Work Experience Fish Management Program on the self-concept of college students (dissertation). Diss. Abstr. Int. Sect. A Humanit. Soc. Sci. 1990, 50, 3854. Available online: https: / /www.proquest.com/openview / 80378d84f8cf87403caf7d776ed3d17f/1?pq-origsite=gscholar\&cbl=18750\&diss=y (accessed on 31 July 2020).

167. Morgan, B.M. Stress management for college students: An experiential multi-modal approach. J. Creat. Ment. Health. 2017, 12, 276-288. [CrossRef]

168. Muckle, J.; Lasikiewicz, N. An exploration of the benefits of animal-assisted activities in undergraduate students in Singapore. Asian J. Soc. Psychol. 2017, 20, 75-84. [CrossRef]

169. Muellmann, S.; Landgraf-Rauf, K.; Brand, T.; Zeeb, H.; Pischke, C.R. Effectiveness of School-based Interventions for the Prevention and/or Reduction of Psychosocial Problems among Children and Adolescents: A Review of Reviews. Gesundheitswesen 2017, 79, 252-260. [PubMed]

170. Nocentini, S.; Novelli, C.; Campani, D. Animal assisted therapy, 4 paws and 2 feet: 6 steps toward a different future. J. Intellec. Disabil. Res. 2015, 59, 35-36.

171. Pendry, P.; Vandagriff, J.L. Animal Visitation Program (AVP) Reduces Cortisol Levels of University Students: A Randomized Controlled Trial. AERA Open 2019, 5, 2332858419852592. [CrossRef]

172. Pendry, P.; Carr, A.M.; Gee, N.R.; Vandagriff, J.L. Randomized Trial Examining Effects of Animal Assisted Intervention and Stress Related Symptoms on College Students' Learning and Study Skills. IJERPH 2020, 17, 1909. [CrossRef] [PubMed]

173. Pendry, P.; Kuzara, S.; Gee, N.R. Evaluation of undergraduate students' responsiveness to a 4-week university-based AnimalAssisted Stress Prevention Program. IJERPH 2019, 16, 3331. [CrossRef] [PubMed] 
174. Pendry, P.; Kuzara, S.; Gee, N.R. Characteristics of student-dog interaction during a meet-and-greet activity in a university-based Animal Visitation Program. Anthrozoös 2020, 33, 53-69. [CrossRef]

175. Pendry, P.; Carr, A.; Roeter, S.M.; Vandgriff, J.L. Experimental trial demonstrates effects of animal-assisted stress prevention program on college students' positive and negative emotion. HAIB 2018, 6, 81-97.

176. Perry, R. The benefits of human-animal interaction on college campuses. Bachelor Thesis, Worcester Polytechnic Institute, Worcester, MA, USA, 2017.

177. Picard, M.J. Study of the Effect of Dogs on College Students' Mood and Anxiety; Honors College, The University of Maine: Orono, ME, USA, 2015.

178. Polking, A.K.; Cornelius-White, J.H.D.; Stout, T.L. Doggone good? Potential benefits of Assistance Animals for students on college campuses. JPED 2017, 30, 237-250.

179. Quinn, B.L.; Peters, A. Strategies to reduce nursing student test anxiety: A literature review. J. Nurs. Educ. 2017, 56, 145-151. [CrossRef] [PubMed]

180. Ralston, S.L. Rutgers Young Horse Teaching and Research Program: Undergraduate student outcomes. J. Anim. Sci. 2012, 90, 4671-4676. [CrossRef]

181. Renne, K.G. Effects of therapy dogs on participants' anxiety in group discussion. In The Research and Scholarship Symposium; 13 Cedarville University: Cedarville, OH, USA, 2018.

182. Robino, A.E.; Corrigan, V.K.; Anderson, B.; Werre, S.; Farley, J.P.; Marmagas, S.W.; Buechner-Maxwell, V. College Student mental health in an Animal-Assisted Intervention Program: A preliminary study. J. Creat. Ment. Health 2020, 16, 49-58. [CrossRef]

183. Robson, H.A. Equine Assisted Psychotherapy: A Critical Review of the Literature. Ph.D. Thesis, Saybrook University, Pasadena, CA, USA, 2016. Dissertation Abstracts International: Section B: The Sciences and Engineering.

184. Rose, J.F. Therapy horses school nurses in emotional fitness. RN 2008, 71, 18-20. [PubMed]

185. Sanford, M.D. Campus Tails: An on-Campus Therapy-Dog Pilot Program and Feasibility Study. Ph.D. Thesis, Antioch University New England, Keene, NH, USA, 2015. Dissertation Abstracts International: Section B: The Sciences and Engineering.

186. Silas, H.J.; Binfet, J.-T.; Ford, A.T. Therapeutic for all? Observational assessments of therapy canine stress in an on-campus stress-reduction program. J. Vet. Behav. 2019, 32, 6-13. [CrossRef]

187. Sola-Perkins, B. The Impact of the Use of a Professional Therapy Dog on the Sense of School Belongingness and Class Attendance of Students in a Truant's Alternative and Optional Education Program. Ed.D. Dissertation, Edgewood College, Madison, WI, USA, 2019. Dissertation Abstracts International Section A: Humanities and Social Sciences.

188. Stewart, A.; Strickland, O. A companion animal in a work simulation: The roles of task difficulty and prior companion-animal guardianship in state anxiety. Soc. Anim. J. Hum. Anim. Stud. 2013, 21, 249-265. [CrossRef]

189. Stewart, L.A.; Dispenza, F.; Parker, L.; Chang, C.Y.; Cunnien, T. A pilot study assessing the effectiveness of an Animal-Assisted Outreach Program. J. Creat. Ment. Health 2014, 9, 332-345. [CrossRef]

190. Straatman, I.; Hanson, E.K.; Endenburg, N.; Mol, J.A. The influence of a dog on male students during a stressor. Anthrozoös 1997, 10, 191-197. [CrossRef]

191. Swan, A.M. Close encounters of the canine kind: The use of dogs as "canine co-therapists" in psychotherapy. Aust. N. Z. J. Psychiatry 2011, 45, A55.

192. Taylor, L.E.; Shaw, J.M. Interspecies encounter: Documenting the benefits of incorporating fine arts into the Equine Studies curriculum. J.Equine Vet. Sci. 2017, 52, 120. [CrossRef]

193. Thelwell, E.L.R. Paws for Thought: A Controlled Study Investigating the Benefits of Interacting with a House-Trained Dog on University Students Mood and Anxiety. Animals 2019, 9, 846. [CrossRef]

194. Thew, K.R. The Effect of Interaction with a Therapy Dog on College Student Stress Levels as Measured by Physiological Indicators. Ph.D. Thesis, Washington State University, Pullman, WA, USA, 2018. Dissertation Abstracts International: Section B: The Sciences and Engineering.

195. Tobin, K.M. The Relationship between Equine-Assisted Psychotherapy and Client-Therapist Attachment on Symptom Reduction. Ph.D. Thesis, Walden University, Minneapolis, MN, USA, 2020. Dissertation Abstracts International Section A: Humanities and Social Sciences.

196. Tomaszewska, K.; Bomert, I.; Wilkiewicz-Wawro, E. Feline-assisted therapy: Integrating contact with cats into treatment plans. Pol. Ann. Med. 2017, 24, 283-286. [CrossRef]

197. Trammell, J.P. The effect of therapy dogs on exam stress and memory. Anthrozoös 2017, 30, 607-621. [CrossRef]

198. Turner, K.; McCarthy, V.L. Stress and anxiety among nursing students: A review of intervention strategies in literature between 2009 and 2015. Nurse Educ. Pract. 2017, 22, 21-29. [CrossRef]

199. Voelpel, P.; Escallier, L.; Fullerton, J.; Abitbol, L. Interaction between veterans and horses: Perceptions of benefits. J. Psychosoc. Nurs. Ment. Health Serv. 2018, 56, 7-10. [CrossRef]

200. Walsh, F. Human-animal bonds I: The relational significance of companion animals. Fam. Process. 2009, 48, 462-480. [CrossRef]

201. Wheller, E.A.; Faulkner, M.E. The "pet effect": Physiological calming in the presence of canines. Soc. Anim. J. Hum. Anim. Stud. 2015, 23, 425-438. [CrossRef]

202. Williams, C.L.; Dagnan, E.; Miner, K.M.; Sells, P. The Effect of an Animal-Assisted Intervention on Physiological Measures of Stress and Anxiety in Graduate Professional Physical Therapy Students. OALib J. 2018, 5, 1-16. [CrossRef]

203. Wilson, C.C. Physiological responses of college students to a pet. J. Nerv. Ment. Dis. 1987, 175, 606-612. [CrossRef] 
204. Wilson, C.C. The pet as an anxiolytic intervention. J. Nerv. Ment. Dis. 1991, 179, 482-489. [CrossRef]

205. Wood, E.; Ohlsen, S.; Thompson, J.; Hulin, J.; Knowles, L. The feasibility of brief dog-assisted therapy on university students stress levels: The PAwS study. J. Ment. Health 2018, 27, 263-268. [CrossRef] [PubMed]

206. Young, J.S. Pet therapy: Dogs de-stress students. JCN 2012, 29, 217-221. [CrossRef]

207. Zents, C.E.; Fisk, A.K.; Lauback, C.W. Paws for intervention: Perceptions about the use of dogs in schools. J. Creat. Ment. Health 2017, 12, 82-98. [CrossRef]

208. Kolcaba, K. Evolution of the mid range theory of comfort for outcomes research. Nurs. Outlook 2001, 49, 86-92. [CrossRef] [PubMed]

209. Health Knowledge. Continuous Outcomes. 2020. Available online: https:/ /www.healthknowledge.org.uk/interactive-learning/ fae/making-sense-of-results/outcome-measures/continuous-outcomes (accessed on 30 July 2020). 